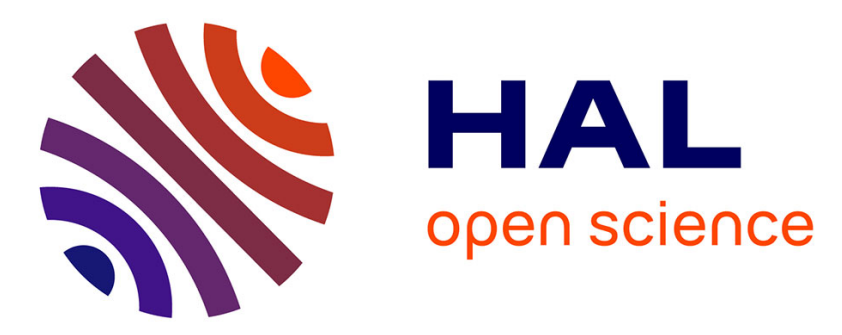

\title{
Supervisory control of building heating system with insulation changes using three architectures of neural networks
}

\author{
Ahmed Ouaret, Hocine Lehouche, Boubekeur Mendil, Hervé Guéguen
}

\section{To cite this version:}

Ahmed Ouaret, Hocine Lehouche, Boubekeur Mendil, Hervé Guéguen. Supervisory control of building heating system with insulation changes using three architectures of neural networks. Journal of The Franklin Institute, 2020, 357 (18), pp.13362-13385. 10.1016/j.jfranklin.2020.09.027 . hal-03040330

\author{
HAL Id: hal-03040330 \\ https://hal.science/hal-03040330
}

Submitted on 10 Dec 2020

HAL is a multi-disciplinary open access archive for the deposit and dissemination of scientific research documents, whether they are published or not. The documents may come from teaching and research institutions in France or abroad, or from public or private research centers.
L'archive ouverte pluridisciplinaire HAL, est destinée au dépôt et à la diffusion de documents scientifiques de niveau recherche, publiés ou non, émanant des établissements d'enseignement et de recherche français ou étrangers, des laboratoires publics ou privés. 


\title{
Supervisory Control of Building Heating System with Insulation Changes Using Three Architectures of Neural Networks
}

\author{
Ahmed OUARET $^{1 *}$, Hocine LEHOUCHE ${ }^{2}$, Boubekeur MENDIL ${ }^{3}$, Hervé GUEGUEN ${ }^{4}$ \\ ${ }^{1,2,3}$ Laboratoire de Technologie Industrielle et de l'Information (LTII), Faculté de Technologie, \\ Université de Bejaia, 06000 Bejaia, Algérie \\ ${ }^{4}$ IETR - CentraleSupelec, Rennes, France \\ *ahmed201189@hotmail.fr \\ *00213795857563
}

\begin{abstract}
This paper presents a new strategy of supervisory control applied to heating room system that is able to adapt to different operating conditions, in order to reduce the energy consumption and guaranteed a good thermal comfort for the occupants. The aim is to design a multi-model and multi-controller supervisor by using neural networks with a view to overcome the limitations of using a single controller and to deal with nonlinearities, parameters uncertainties and the time constant of the heating system. The proposed methodology is based on three model/controller pairs, a monitoring signal generator and a switching logic. Three architectures of neural network architectures, namely multilayer perceptron neural networks, radial basis function and memory neuron networks are used to evaluate this control technique and to design the different controller/model pairs which correspond to the same work office and a specific isolation state. A comparative study is associated to this work in order to recognize the best neural network in terms of performance and simulation time. The results obtained for three scenarios addressed herein show the importance and the effectiveness of this method.
\end{abstract}

Keywords: Supervisory control, neural networks, thermal control, building control

\section{Introduction}

Buildings are considered as a major consumer of energy among all economic sectors. They account for about $31 \%$ of the global energy used in the world [1]. This part of the consumption increases continuously due to the high rate of urbanization, climate change, and other driving factors [2, 3, 4]. Nearly half of this energy is related to heating, ventilation and air conditioning (HVAC) systems [5]. Reducing the building energy costs has become an urgent task, due to the increasing environmental concerns and energy price. It is important that these systems are well controlled in order to reduce energy consumption and to maintain good comfort for the occupants.

Different types of controllers of heating systems may be used to optimize the energy efficiency and to ensure a certain level of comfort for the occupants, these controllers are of type proportional-integralderivative (PID) controllers, auto-tuning methods of PID parameters [6, 7], fuzzy logic controllers [8], genetic algorithms [9], distributed iterative learning temperature control [10], predictive control [11, 12] and other work such as $[13,14,15,16,17,18,19,20]$. All these methods require adjustments and are generally based on linear model. They have a single controller that does not guarantee the desired behaviour, or they do not take into consideration climate changes and the different disturbances that affect the system, making them unsatisfactory or limited. Therefore, it seems to be prominent to search for a new advanced approach or algorithm that is able to maintain the desired behaviour in the presence of various disturbances, for this purpose, we have developed a supervisory control technique based on three model/controller pairs applied to this heating system by taking into consideration situations and circumstances. Three neural network architectures have been used to evaluate this control method.

Recently, a growing interest has been granted to the advanced control strategies based on supervisory and switching algorithms to control complex and nonlinear systems. Several controllers are defined for different operating environments. A supervisor based on a switching logic makes it possible to determine at each instant the operating mode of the system and to select the appropriate controller. The logic of this selection is based on the values of monitoring signals, which are obtained by taking 
performance criteria based on the multi-model estimation errors. The principal idea behind the switching strategy is to determine which of the monitoring signals is the smallest, which permits to choose the corresponding controller [21]. The need for switching stems from the fact that generally no single controller can guarantee the desired behaviour when connected with the complex nonlinear poorly modeled process. Different schemes for supervisory control based on switching logic algorithms have been presented in the literature, which differ on when and how to choose the suitable controller $[22,23$, 24].

On the other hand, our vision is to use an intelligent technique based on learning to overcome the limitations of conventional methods which have often shown their inadequacy, especially when the systems to be studied present high non-linearities. The failure of classical methods is due to the lack of a priori knowledge necessary for the elaboration of the mathematical model. In the face of this problem, it is possible to use neural networks (NNs). The use of these neural networks to design identifiers and controllers has increased significantly in recent years [25]. NNs can be considered as universal approximators $[26,27]$ that have a capacity to adapt to a dynamic that evolves over time. The various applications related to energy management in buildings increase considerably. Artificial neural networks (ANNs) have been used for HVAC control [28, 29, 30], in the prediction of energy consumption [31], in wind energy systems [32, 33, 34], in renewable energy systems [35, 36] and for fault diagnostic [37].

This paper is an extension of [38] and its novelty is to add other neural networks architectures and integrating the hysteresis to avoid the frequent switching between various controllers. This can overcome the oscillations in the indoor temperature and ensure the perfect tracking of setpoint. The case study is a working office in a building that can be considered as a complex nonlinear process taken from the Simbad toolbox integrated in Matlab [39]. The control proposed in this paper is more adapted to different situations, it consist of three model/controller pairs, a monitoring signal generator and a switching logic. Each pair corresponding to the same working office, which defined for three states of insulation (well, medium and poorly insulated). To evaluate the proposed method we used two feedforward neural networks namely, multilayer perceptron neural networks (MLP) and radial basis function (RBF), and a recurrent network which is the memory neuron networks (MNN) [40, 41, 42]. The aim of this controller is to regulate the ambient temperature inside this office in order to guarantee a perfect tracking of the desired temperature in order to maintain a good comfort and to reduce the waste of energy, in spite of the presence of different disturbances and constraints. This work is fulfilled by a comparative study between these architectures in order to choose the best one.

The remainder of the paper is organized as follows: Section 2 describes the process. Section 3 is devoted to recall the methodology of identification and supervisory control using three architectures of neural networks (MLP, RBF and MNN). Application of these neural networks for identification and supervisory control for regulating the ambient temperature in building zone is the subject of section 4 . Conclusions and perspectives are drawn in the last section.

\section{The building zone with electrical heater case study}

\subsection{Zone model description}

A building zone model consists of a detailed envelope, simplified radiation and convection submodels. A central node has been used to represent the resultant temperature in the zone. The different inputs and output of the model are described in Fig. 1. 


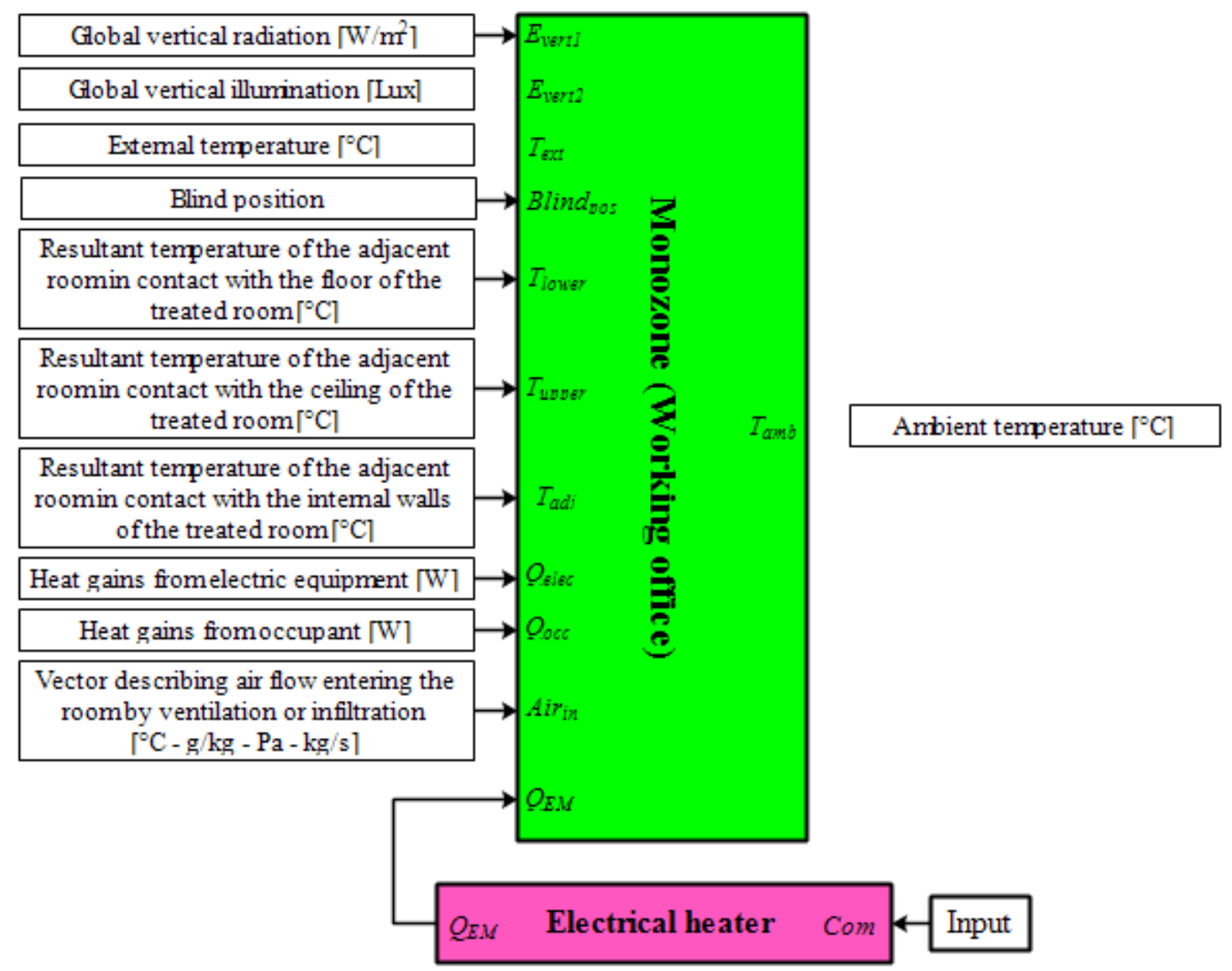

Fig. 1. The simulation model of the room with different inputs and output

The Fig. 1 represents the inputs and output of the monozone building heating system (working office) which is depicted directly from Simulink/Simbad environment [39]. These inputs can be divided into five groups:

1. The inputs provided by the weather data $\left(E_{\text {vert } 1}, E_{\text {vert } 2}, T_{\text {ext }}, A i r_{i n}\right)$, their values are given by the integrated toolbox SIMBAD and correspond to good approximation to values encountered in practice.

2. Blind position input which switches between open and close position $\left(\right.$ Blind $\left._{p o s}\right)$.

3. The heat gains delivered by the electrical equipment and the occupants $\left(Q_{\text {elec }}, Q_{o c c}\right)$.

4. The resultant temperature of the adjacent room in contact with the floor, the ceiling and the internal walls of the treated room $\left(T_{\text {lower }}, T_{\text {upper }}, T_{\text {adj }}\right)$.

5. The heat flux provided by the electrical heater $Q_{E M}[w]$.

The output taken into account is the ambient temperature inside the room $\left(T_{a m b}\right)$.

The electrical heater has a normalized control input limited between 0 and 1 which is used to control the heat flux $Q_{E M}[w]$.

\subsection{Simulation parameters}

The case study chosen for application is an office room, these types of buildings are occupied only during working days between certain hours relatively fixed between $8 \mathrm{~h} 00$ and $17 \mathrm{~h} 00$. The room characteristics used for simulation are given in Table 1. 
The different values mentioned below (heat emission equipment per $\mathrm{m}^{2}$, Fresh air supply, mean outside temperature) are default values proposed by SIMBAD (toolbox) and they represent good approximations for the values encountered in practice.

Table 1

Simulation parameters

\begin{tabular}{|c|c|}
\hline Designation and heat transfer factor & Dimension \\
\hline Room dimensions & $4 \times 4 \times 3 \mathrm{~m}^{3}$ \\
\hline Window surface & $2 \mathrm{~m}^{2}$ (closed during the period of occupation) \\
\hline Wall, floor and ceiling heat transfer coefficients & {$\left[\begin{array}{llll}0.25 & 0.0001 & 0.25\end{array}\right] \mathrm{W} / \mathrm{m}^{2} / \mathrm{k}$} \\
\hline Initial temperature & $10^{\circ} \mathrm{C}$ \\
\hline Reference temperature while occupancy & $19^{\circ} \mathrm{C}$ \\
\hline Electric heater nominal power & $1500 \mathrm{~W}$ \\
\hline Number of occupants & 2 persons \\
\hline Weather data $\left(E_{\text {vert } 1}, E_{\text {vert } 2}, T_{\text {ext }}\right)$ & Rennes (region in France) \\
\hline Heat emission equipment per $\mathrm{m} 2$ & $1 \mathrm{~W} / \mathrm{m}^{2}$ \\
\hline Fresh air supply & $40 \mathrm{~m}^{3} / \mathrm{h} /$ pers \\
\hline Mean outside temperature & $6.5^{\circ} \mathrm{C}$ \\
\hline
\end{tabular}

\section{Artificial neural networks (ANNs)}

ANNs are the distributed processing systems that have been inspired from the biological nerve system, which consists of processing elements (neurons), and association between them with weights that constitute the neuronal structure.

The three neural network architectures utilized in this article have been used in many applications either for identification or for control [25]. The first (MLP) is considered as the most widely used network in the literature, the second (RBF) has recently attracted a great deal of attention due to its good generalization capability and a simple network structure that avoids unnecessary and lengthy computations. The third is a recurrent network. The three types of networks have been used to determine which network gives the best results for this application.

\subsection{Multilayer perceptron neural networks architecture}

The MLP neural networks is a class of feedforward neural networks; the network is composed of an input layer, one or more hidden layers and one output layer. Each layer has a specific number of neurons which are the basic processing elements of artificial neural networks. The neurons in layer $l$ are associated with the other neurons in layer $l+1$ by weights $[43,44]$. Neurons in the input layer have generally a linear activation function, the hidden and output layers use some nonlinear activation functions such as tangent sigmoid and logarithmic functions. A structure of an MLP neural network with two hidden layers and one neuron in the output layer is presented in Fig. 2.

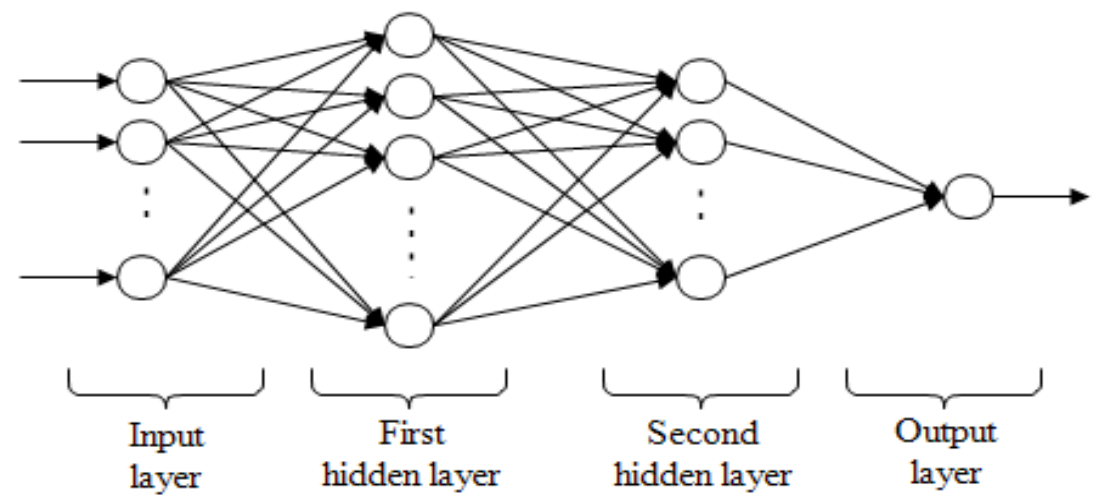


Fig. 2. Structure of an MLP neural network with two hidden layers

The output of the $j t h$ neuron in layer $l$ at time $k$ is given by equation (1)

$$
y_{j}^{l}(k)=f\left(\sum_{i=1}^{N_{l-1}} w_{i j}^{l-1}(k) y_{i}^{l-1}(k)\right) ; j=1,2, \ldots, N_{l} ; l=1,2, \ldots, L
$$

where $w_{i j}^{l-1}$ is the connection weight between the ith neuron of layer $l-1$ to $j t h$ neuron of layer $l, L$ the number of layer including hidden and output, $N_{l}$ the number of neuron in layer $l$ and $f($.) the activation function.

\subsection{Radial basis function neural networks architecture}

Recently, RBF neural networks have drawn much attention and are considered as the neural network type most used after the MLP because of their good generalization ability and a simple network structure that avoids useless and long computation. Previous research on the approximation theorems using these networks showed that any nonlinear function over a compact set could be approximated with arbitrary accuracy by RBF neural networks [45, 46, 47]. Moreover, RBF neural networks can be used to control of complex nonlinear systems $[48,49,50]$.

RBF neural networks have three layers called input, hidden and output layers. Neurons in the hidden layer are activated by a radial basis function. The RBF structure is illustrated in Fig. 3

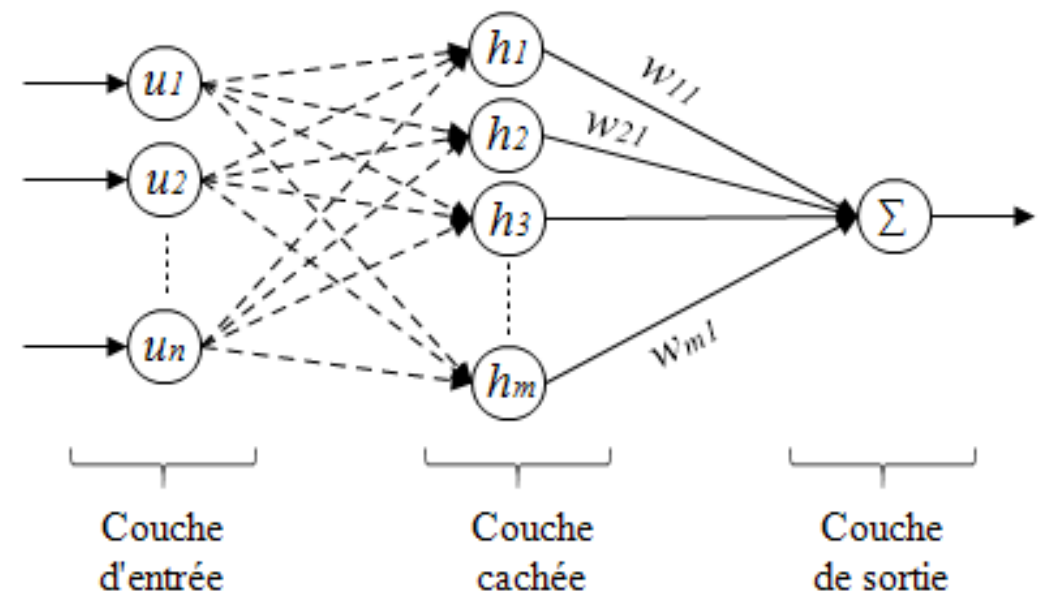

Fig. 3. Structure of an RBF neural network

The output of the $j t h$ neuron in the output layer is given by equation (2)

$$
y_{j}=\sum_{i=1}^{m} w_{i j} h_{i}(u) ; \quad j=1,2, \ldots, L
$$

where $w_{i j}$ is the connection from ith neuron of hidden layer to $j t h$ neuron of output layer, $m$ is the number of neurons in hidden layer, $L$ the number of neurons in output layer and $h_{i}(u)$ the radial basis gaussian function given by equation (3).

$$
h_{i}=\exp \left(-\frac{\left\|u-c_{i}\right\|^{2}}{2 \sigma_{i}^{2}}\right) ; \quad i=1,2, . ., m
$$

where $c_{i}=\left[c_{p i}\right]$ is the center of gaussian functions, $u=\left[u_{p}\right]$ is the input vector, $p=1,2, \ldots, n$ and $\sigma_{i}$ is the widths of gaussian functions.

\subsection{Memory neural networks architecture}


The structure of MNN used in this paper is similar to the one reported in [41]. The structure is the same as that of a feed-forward artificial neural networks aside from the memory neurons attached to each network unit. The memory neuron takes its input from its self-feedback and the corresponding neuron. This conduct to accumulation of past data of the neuron in the memory. All the memory neurons and the neurons of each level send their outputs to the neurons of the following level. In the output layer, each neuron can have one or a cascade of memory neurons and each sends its output to that neuron in the output layer. A structure of an MNN neural network with two input nodes, one output node and a single hidden layer is presented in Fig. 4.

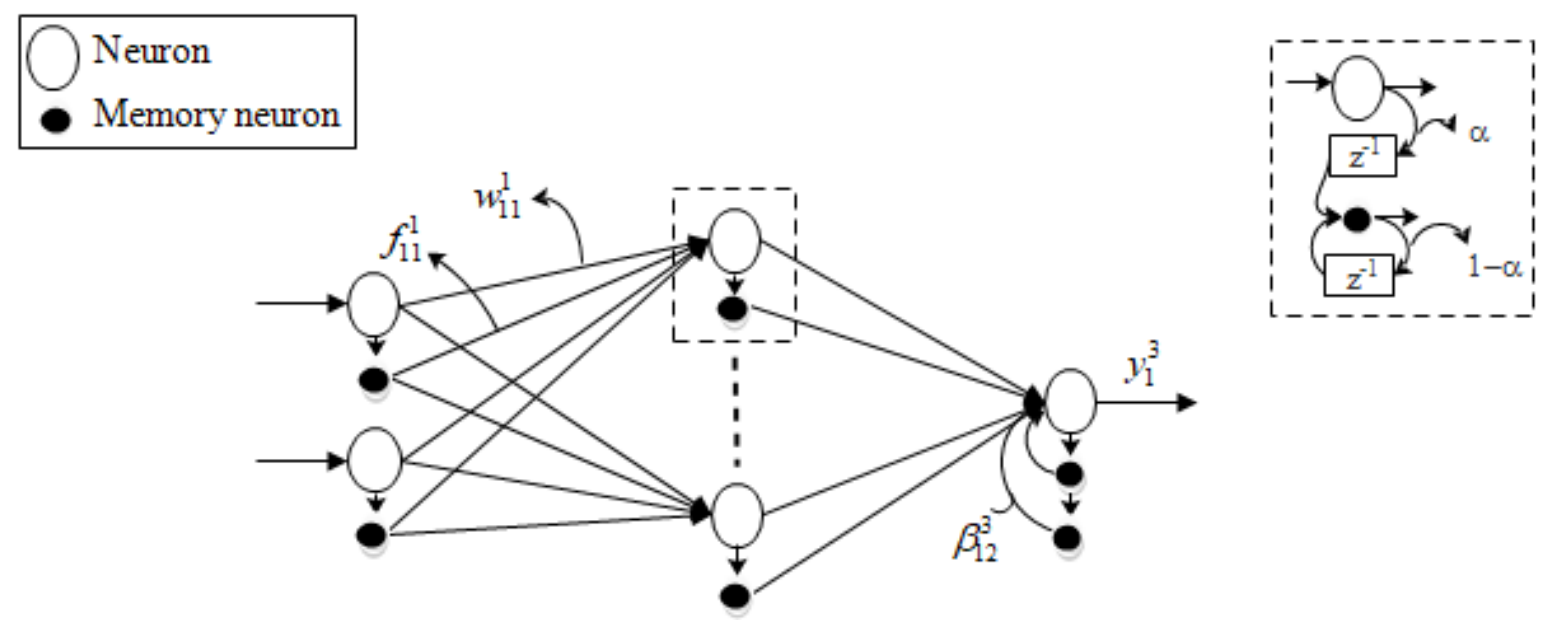

Fig. 4. Structure of an MNN

The output of each element of layer $l, 1 \leq l<L$ at time $k$ is given by equation (4) and the output of output layer according to (5).

$$
\begin{aligned}
& y_{j}^{l}(k)=f\left(\sum_{i=0}^{N_{L-1}} w_{i j}^{l-1} y_{i}^{l-1}(k)+\sum_{i=1}^{N_{L-1}} f_{i j}^{l-1} v_{i}^{l-1}(k)\right) \\
& y_{j}^{L}(k)=\sum_{i=0}^{N_{L-1}} w_{i j}^{L-1} y_{i}^{L-1}(k)+\sum_{i=1}^{N_{L-1}} f_{i j}^{L-1} v_{i}^{L-1}(k)+\sum_{i=1}^{M_{j}} \beta_{j i}^{L} v_{j i}^{L}(k)
\end{aligned}
$$

where $w_{i j}^{l-1}$ is the weight of the connection from the $i$ th neuron of layer $l-1$ to $j t h$ neuron of layer $l, v_{i}^{l-1}$ is the output of the memory neuron of the ith neuron in layer $l-1,1 \leq l<L . f_{i j}^{l-1}$ is the weight of the connection from the memory neuron corresponding to the ith neuron of layer $l-1$ to the $j$ th neuron of layer $l, \beta_{j i}^{L}$ is the weight of connection from the $i t h$ memory neuron of the $j t h$ neuron to the $j t h$ neuron in the output layer, $M_{j}$ the number of memory neurons associated with the $j$ th neuron of the output layer and $f($.$) the activation function.$

The output of all memory neurons except for those of the output layer is given equation (6) and the memory neurons in the output layer according to (7).

$$
\begin{aligned}
& v_{j}^{l}(k)=\alpha_{j}^{l} y_{j}^{l}(k-1)+\left(1-\alpha_{j}^{l}\right) v_{j}^{l}(k-1) \\
& v_{j i}^{L}(k)=\alpha_{j i}^{L} v_{j i-1}^{L}(k-1)+\left(1-\alpha_{j i}^{L}\right) v_{j i}^{L}(k-1)
\end{aligned}
$$


where $\alpha_{j i}^{L}$ is the weight of the connection from the $(i-1) t h$ memory neuron to the $i t h$ memory neuron of the $j$ th neuron in the output layer.

\section{4 learning algorithm of the three neural networks}

The neural networks learn by adapting their weights according to some specified rule called learning algorithm. Many different learning algorithms have been reported in the literature, among these algorithms we can quote, methods of the gradient descend [51, 52, 53], RTRL [54] and ALOPEX [55] for MLP and MNN; Least mean square [56], particle swarm optimization [57] genetic algorithm [58] for RBF.

Throughout this paper, we have used online learning algorithm for perceptron training, which depends on instantaneous error. The main purpose is to adjust the connection weights, in view of minimizing the prediction error made by the perceptron in its current state. The great advantage of this learning strategy seems to be more dynamic, in updating the current estimate based on the observation of one by one new data. The algorithm delineated previously takes into account the observing data iteratively and gradually, it demands less memory, few calculations, real time adaptation and it undergoes the order in which the observations are accessible. This learning procedure is generally slow but is recommended to this case of study.

\section{Application of different structures of neural networks for identification and supervisory control of the building heating system}

\subsection{Identification of the process in open loop}

As we mentioned in the introduction, the objective of identification algorithm is to select and to compute a consistent model with observation of the output of the system. For identification of the system described in section 2, we have picked three structures of neural networks used as an identifier. To take into account the dynamic aspect of the process, the input vector of the network is often reinforced by signals corresponding to the previous values of the outputs of the system or network. In our case, we use the process outputs (Fig. 5), which is named series-parallel structure.

The neural networks identifiers have two inputs and one output as illustrated in Fig. 5. The neural networks are trained online, and produces an appropriate ambient temperature in order to track that of system. The hidden layers have nonlinear activation functions which are the sigmoid (8) for MLP and MNN, the gaussian (3) for RBF, and the output layer have a linear activation function. The MLP and RBF weights are updated according to the errors between network output and desired output. Hence, this algorithm was called as a back propagation algorithm [51,52], and the MNN weights are updated by using the squared error criterion and the back-propagation algorithm [53].

$$
f(x)=\frac{1}{1+e^{-x}}
$$

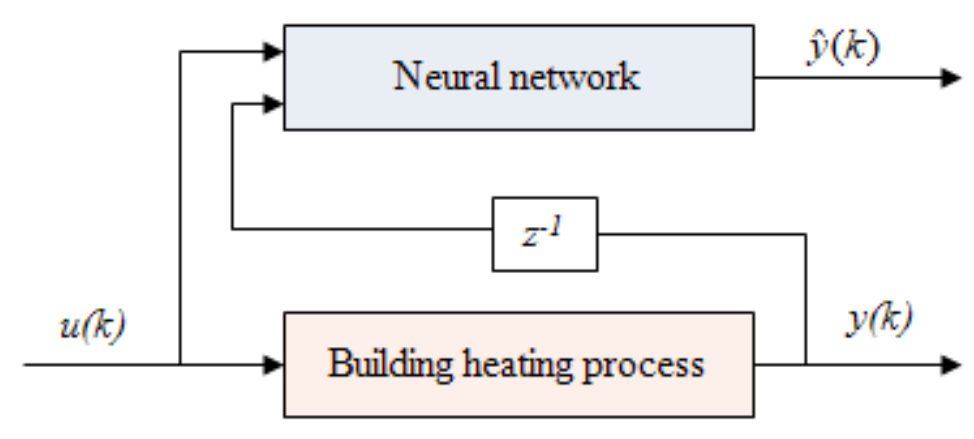


Fig. 5. Series-parallel identification structure

The parameters of the identifiers are updated by using the equations below.

$$
\begin{aligned}
& \hat{y}(k)=R N_{\rho}(u(k), y(k-1)) \\
& \rho_{k+1}=f\left(\rho_{k}, e_{i}(k)\right) ; \text { where } e_{i}(k)=(y(k)-\hat{y}(k))
\end{aligned}
$$

where $R N$ is the neural network, $\hat{y}(k)$ is the output of identifier at time $k, k \in\left[t_{0}-t_{f}\right]$ training period, $u(k)$ is the input of system, $y(k)$ is the output of system, $e_{i}(k)$ the identification error at time $k, \rho_{k}$ parameter vector at time $k$ and $f($.) the learning algorithm used to adjust the different parameters of the neural networks.

\subsubsection{Simulation results}

Now that, the three structures of neural networks have been chosen, we can consider the results obtained by applying this approach to the case of a building during one day, for a sampling time of 200s, which let us to define the training base of samples. Note that in our scenario, the external temperature varies according to the conditions of Rennes weather data.

We note that, after several simulations experiences the number of layers and neurons of each network as shown in Table 2 is sufficient to get the desired results and to avoid the complexity of the model.

Table 2

Identifiers structure (MLP, RBF and MNN)

\begin{tabular}{llll}
\hline Architecture & MLP & RBF & MNN \\
\hline Input neurons & 2 & 2 & 2 \\
Output neurons & 1 & 1 & 1 \\
Hidden layer & 2 & 1 & 1 \\
Hidden neurons in first layer & 5 & 3 & 3 \\
Hidden neurons in second layer & 6 & $/$ & $/$ \\
Input memory & $/$ & $/$ & 2 \\
Hidden memory in hidden layer & $/$ & $/$ & 3 \\
Output memory & $/$ & $/$ & 3 \\
\hline
\end{tabular}

The figure below is obtained after several experiments from which we have taken the parameters adjusted and injected them again in order to guarantee a good follow-up even at the beginning of the simulation period, so this figure represents the result of the last experience applied to the learning sequence.

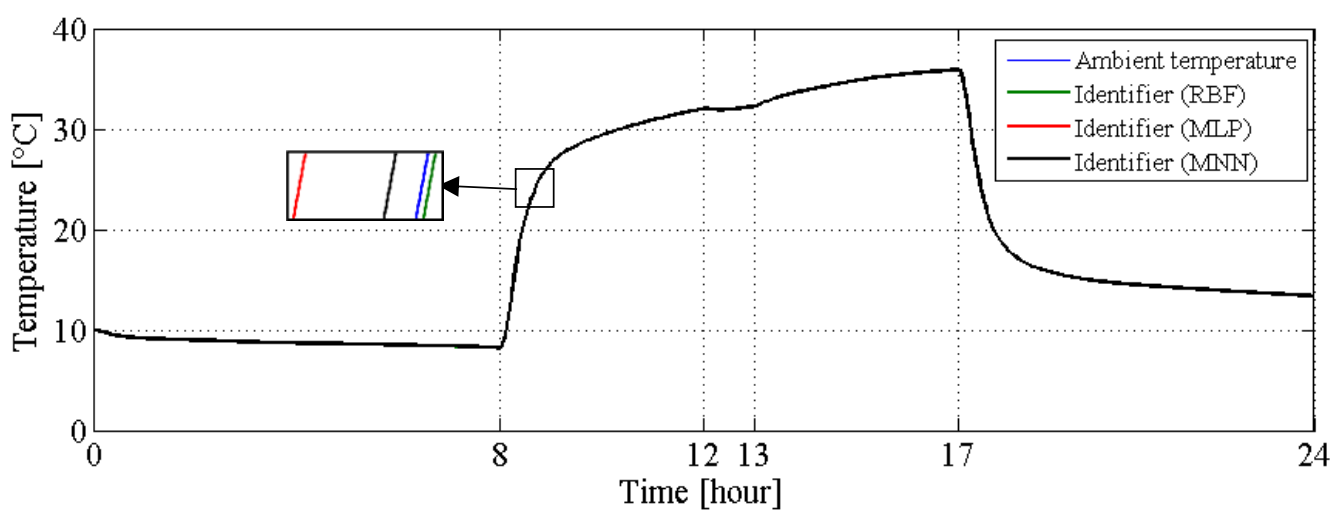

Fig. 6. The outputs of identifiers and system during training phase

As indicated in Fig. 6, we can observe that the output of the three neural networks models have followed the desired output during the training phase with a very small mean square errors as shown in 
Table 3.

\subsubsection{Validation}

To validate the performance of the identifiers, we use these neural networks identifiers on another day whose weather conditions are not the same as the first region (Nancy region). Fig. 7 represents the desired output and the three neural networks identifiers (models) outputs during validation phase, and the validation errors are shown in Table 3.

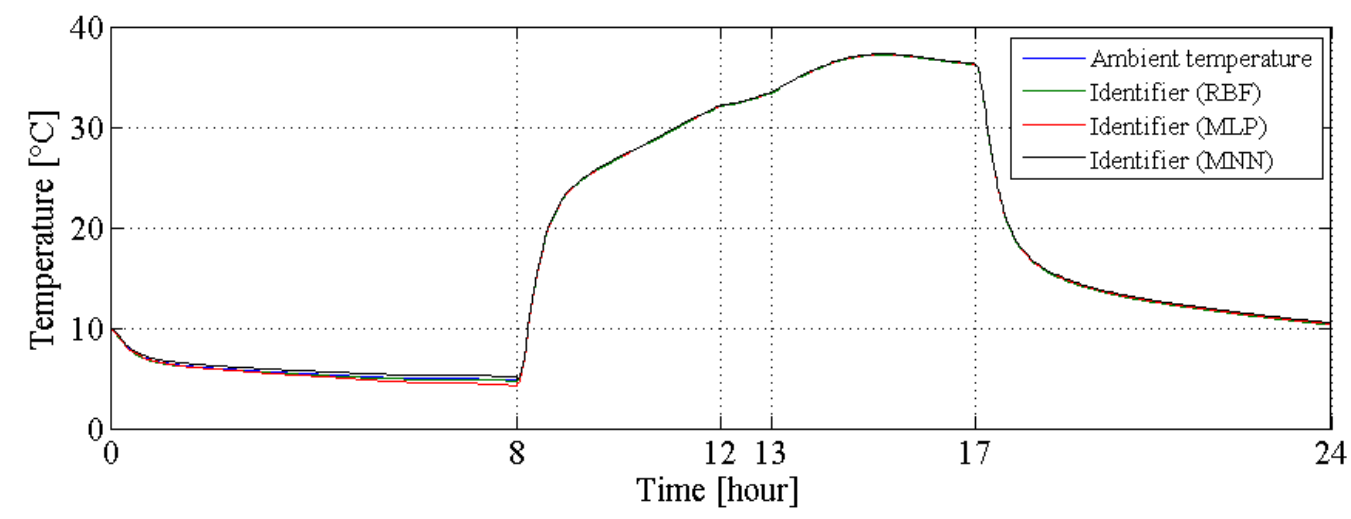

Fig. 7. The outputs of identifiers and system during validation phase

To evaluate performance of these network architectures for identification and to compare between them, we have used the mean square error (MSE) criteria that is classical index to validate the performance of the model as in [25, 40, 42].

This performance index (MSE) is given according to the error signal as shown in equation (11).

$$
M S E=\frac{1}{N} \sum_{k=1}^{N}(\hat{y}(k)-y(k))^{2}
$$

where $\hat{y}(k)$ is the output of the identifier and $y(k)$ is the ambient temperature output of the system.

The Table 3 represents the performance index for the three architectures used for identification.

Table 3

Mean Square Error (MSE) during the occupation period

\begin{tabular}{llll}
\hline & MLP & RBF & MNN \\
\hline MSE training & $1.0799 \times 10^{-12}$ & $5.8487 \times 10^{-8}$ & $1.7758 \times 10^{-9}$ \\
\hline MSE validation & 0.0013 & 0.0051 & 0.0010 \\
\hline
\end{tabular}

As indicated in Fig. 7, we can observe that the output of the three neural networks models have followed the desired output during the validation phase with a very small mean square errors as shown in Table 3. The change of the region and the presence of the different disturbances have no influence on the output response of the system. These results show the capacity and the effectiveness of these kinds of networks (MLP, RBF and MNN) for the identification of highly nonlinear thermal systems.

We can also see in table 3 that the error with MNN is small compared to the others, which reflects the good tracking of the desired output.

\subsection{Neural networks for control}

The three neural networks controllers have four inputs and one output as illustrated in Fig. 9. The neural networks are trained online, and produce control in order to track the setpoint. The activations functions of the hidden layers for the MLP and RBF are the sigmoid (8), the gaussian (3) for RBF, and 
the output layer have a linear activation function. The parameters of the controllers are updated by using the error between the output of the process and the reference model.

The parameters of the controllers are updated by using the equations below.

$$
\begin{gathered}
u(k)=R N_{\rho}\left(y_{r}(k), y(k), y(k-1), u(k-1)\right) \\
\rho_{k+1}=f\left(\rho_{k}, e_{c}(k)\right) ; \text { where } e_{c}(k)=\left(y_{r}(k)-y(k)\right)
\end{gathered}
$$

where $R N$ is the neural network, $y(k)$ is the output of the process at time $k, k \in\left[t_{0}-t_{f}\right]$ training period, $y_{r}(k)$ the setpoint, $u(k)$ is the input of process, $\rho_{k}$ parameter vector at time $k, e_{c}(k)$ the control error at time $k$ and $f($.$) the learning algorithm used to adjust the different parameters of the neural networks.$ The control structure is given in Fig. 9.

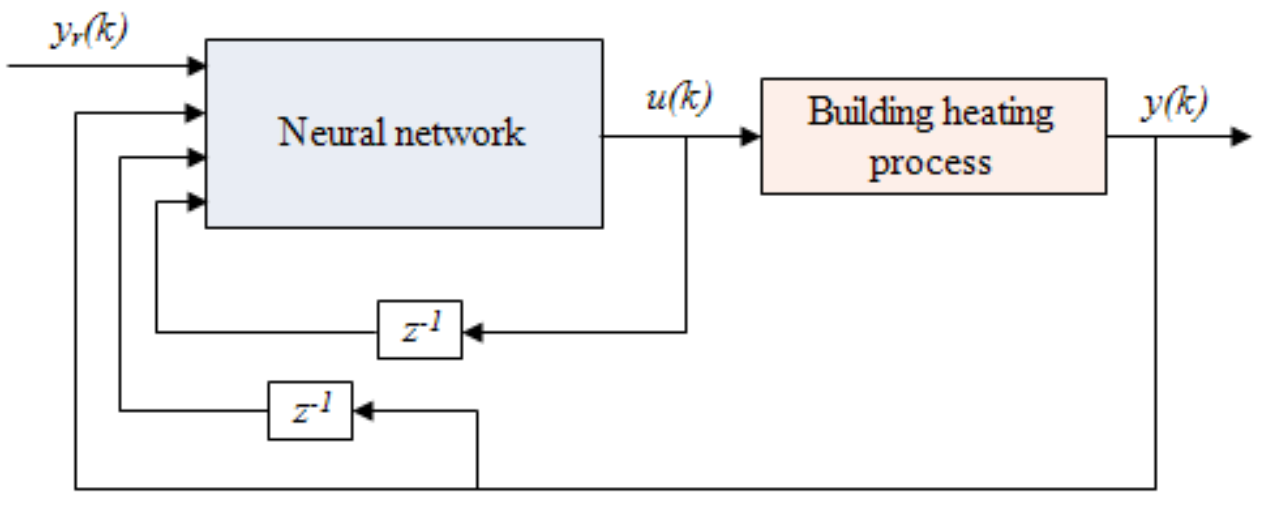

Fig. 9. Control structure

The learning procedure applied for the three types of models corresponding to the same working office (zone), which defined for three states of insulation well, medium and poor with these respective coefficients vectors

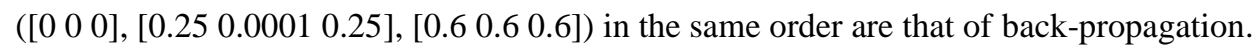

For various network architectures leads to a choice of unique structure that is given in Table 4 .

Table 4

Controllers structures

\begin{tabular}{llllllllll}
\hline & \multicolumn{1}{l}{ MLP } & \multicolumn{9}{l}{ RBF } & \multicolumn{7}{c}{ MNN } \\
\cline { 2 - 10 } & Cont1 & Cont2 & Cont3 & Cont1 & Cont2 & Cont3 & Cont1 & Cont2 & Cont3 \\
\hline Hidden layer & 1 & 1 & 1 & 1 & 1 & 1 & 1 & 1 & 1 \\
Input neurons & 4 & 4 & 4 & 4 & 4 & 4 & 4 & 4 & 4 \\
Hidden neurons & 6 & 6 & 6 & 6 & 6 & 6 & 6 & 6 & 6 \\
Output neurons & 1 & 1 & 1 & 1 & 1 & 1 & 1 & 1 & 1 \\
Input memory & $/$ & $/$ & $/$ & $/$ & $/$ & $/$ & 4 & 4 & 4 \\
Hidden memory & $/$ & $/$ & $/$ & $/$ & $/$ & $/$ & 6 & 6 & 6 \\
Output memory & $/$ & $/$ & $/$ & $/$ & $/$ & $/$ & 3 & 3 & 3 \\
\hline
\end{tabular}

We have simulated the heating system several times on a one-day profile in order to show the performance of each controller on the different configurations (models). To evaluate performance of these network architectures for control, we have used the mean square error (MSE) criteria given by equation (14).

$$
M S E=\frac{1}{N} \sum_{k=1}^{N}\left(y_{r}(k)-y(k)\right)^{2}
$$

where $y_{r}(k)$ is the setpoint and $y(k)$ the ambient temperature output of the system.

The Table 5 represent the performance of each pair controller/model for the three stuctures of neural networks given in the Table 4 by using equation (14). 
Table 5

Mean Square Error (MSE) during the occupation period

\begin{tabular}{llll}
\hline Controller/Model & MLP & RBF & MNN \\
\hline Cont1/Model1 & 0.0077 & 0.0086 & 0.0053 \\
Cont1/Model2 & 0.2176 & 0.2002 & 0.2045 \\
Cont1/Model3 & 3.64 & 4.0752 & 3.6498 \\
& & & \\
Cont2/Model1 & 0.0653 & 0.1111 & 0.0240 \\
Cont2/Model2 & 0.0075 & 0.0200 & 0.0123 \\
Cont2/Model3 & 0.2436 & 0.2850 & 0.3560 \\
Cont3/Model1 & 0.1238 & 0.0890 & 0.0830 \\
Cont3/Model2 & 0.0495 & 0.0212 & 0.0683 \\
Cont3/Model3 & 0.0121 & 0.0183 & 0.0205 \\
\hline
\end{tabular}

From Table 5, we can see that the performance of each controller is good for the model it has been trained for and less good for the other models. For this, it seems that the supervised control is a solution to ensure a good tracking of the setpoint in order to maintain good comfort for the occupants, what we explain in the next subsection.

\subsection{Supervisory adaptive control of nonlinear systems}

The proposed supervisory control architecture facilitates the decision-making task related to control actions for enhancing the operation of complex dynamic processes which may consist of interconnected subsystems characterized according to various operating modes and conditions, generally subjected to external disturbances [59]. This structure is made out of two levels, named regulatory control level and supervisory level. A supervisor based on a switching logic allows to determine at any time the effective mode of the systems and to select the appropriate controller.

Fig. 8 represents the supervisory control scheme introduced initially in [60] and discussed by such others as in [21, 61, 62], which contains several models, a monitoring signal generator and switching logic that allow choosing the selection of the appropriate controller.

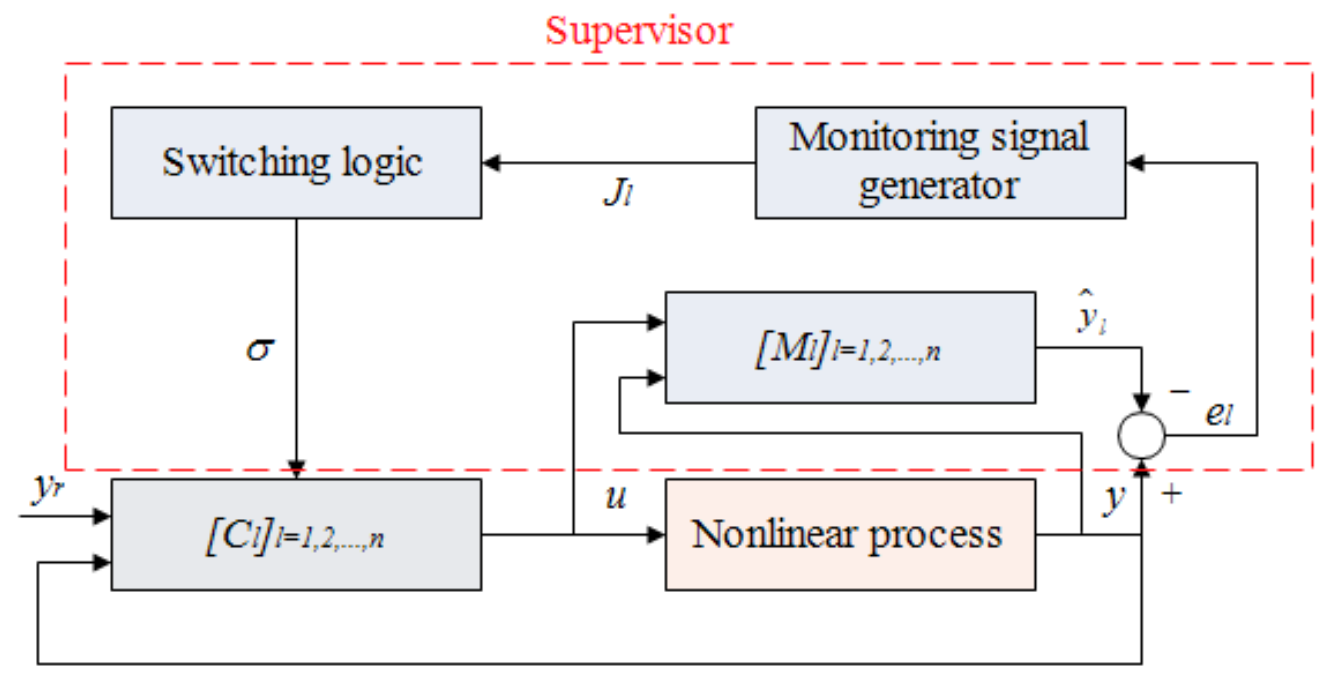

Fig. 8. Supervisory control architecture

First, each model $M_{l}$ generates an estimated output $\hat{y}_{l}$. The difference between $\hat{y}_{l}$ and $y$ gives an 
estimation error $e_{l}(k)=y(k)-\hat{y}_{l}(k)$. These errors are translated into performance indices $J_{l}>0$ by the monitoring signal generator, which express the fitness of the models. A popular choice of performance criteria is given below.

$$
J_{l}(k)=\alpha_{l} e_{l}^{2}(k)+\beta_{l} \sum_{j=0}^{k} \rho_{l}^{k-j} e_{l}^{2}(j) ; \quad(l=1, \ldots, n)
$$

The designed parameters $\left(\alpha_{l}, \beta_{l}, \rho_{l}\right)$ are positives, where $\alpha_{l}$ and $\beta_{l}$ are used respectively to weight the impact of the instantaneous measures given by $e_{l}^{2}(k)$ and long-term ones given by the second part $\sum_{j=0}^{k} \rho_{l}^{k-j} e_{l}^{2}(j) \cdot \rho_{l}$ is considered as a forgetting factor that gives more importance to the recent values of the error, $\rho \in[0,1]$. The implementation of the supervisor depends directly on the choice of these parameters. The selection of the best controller is based on the smallest error signal, which correspond to the best performance index $J_{l}$. The presence of noisy measurements and disturbances may cause too fast and frequent switching, which motivated the hysteresis switching logic presented in [29]. Suppose that the last switch occurred at time $t_{j}$ and the switching signal is now $\sigma(t)=l \in I$, where $l$ is the index of the active controller. Under hysteresis switching, the value of $\sigma$ remains fixed until a time $t_{j+1}$, where $(1+h) \min J_{p}\left(t_{j+1}\right) \leq J_{l}\left(t_{j+1}\right)$ under the constant $t_{j+1}>t_{j}+\varepsilon$.

with hysteresis constant $h>0$. The stay time is then bounded below by a limited $\varepsilon$. At $t_{j+1}$, the switching signal takes the value $\sigma(t)=\arg \min _{\rho} J_{l}\left(t_{j+1}\right)$ until the hysteresis exchanging condition is satisfied at the next time.

\subsection{Supervisory adaptive control of temperature regulation in building zone}

In this subsection, we consider the controllers and the models defined previously by adding a monitoring signal generator and switching logic that orchestrate the selection of the appropriate controller, in order to ensure proper monitoring of the setpoint whatever the state of the room.

The selection of the controller is based on the evaluation of the performance criteria $J_{l}$ given in (15) with these parameters $\left(\alpha_{l}=0.5, \beta_{l}=0.7, \rho_{l}=0.9\right.$ for $\left.l=1,2,3\right)$, the hysteresis constant $h=4 \times 10^{-6}$.

\subsubsection{Simulation results}

Three scenarios are considered. The first scenario corresponds to one day for each room configuration, the second corresponds to three working days with a change of configuration and the third one corresponds to a building configuration different from the ones taken before to validate the performance of the proposed approach. The Supervisory adaptive control scheme for temperature regulation in a building zone is presented in Fig. 10. 


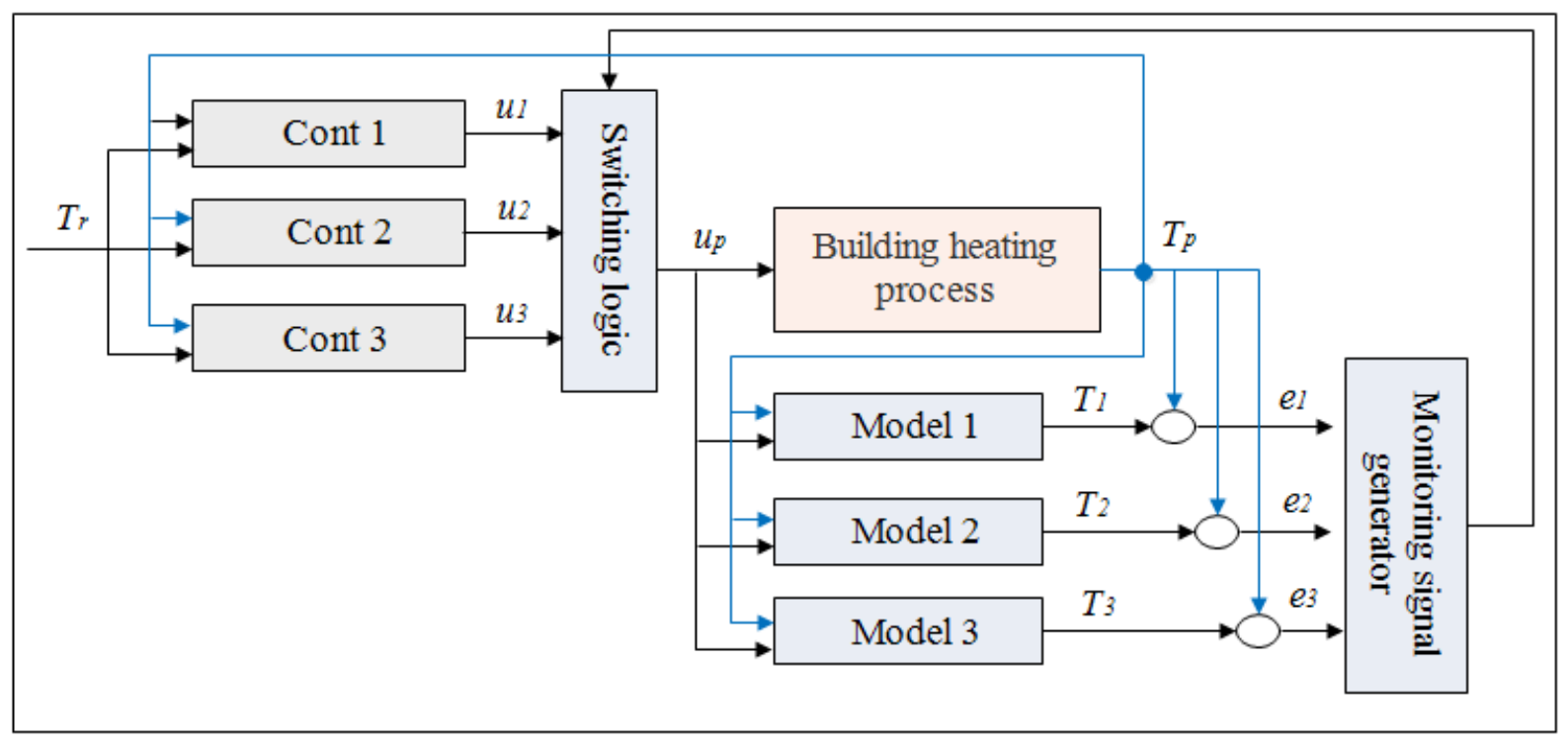

Fig. 10. Supervisory adaptive control scheme for temperature regulation in a building zone

\subsubsection{The first scenario (one day)}

In this scenario, we have simulated the proposed control approach for one day using three structures of neural networks (MLP, RBF and MNN), for three building configurations.

\section{a.First case}

The simulation results concern the well-insulated zone are given in Figs. 11, 12 and 13.

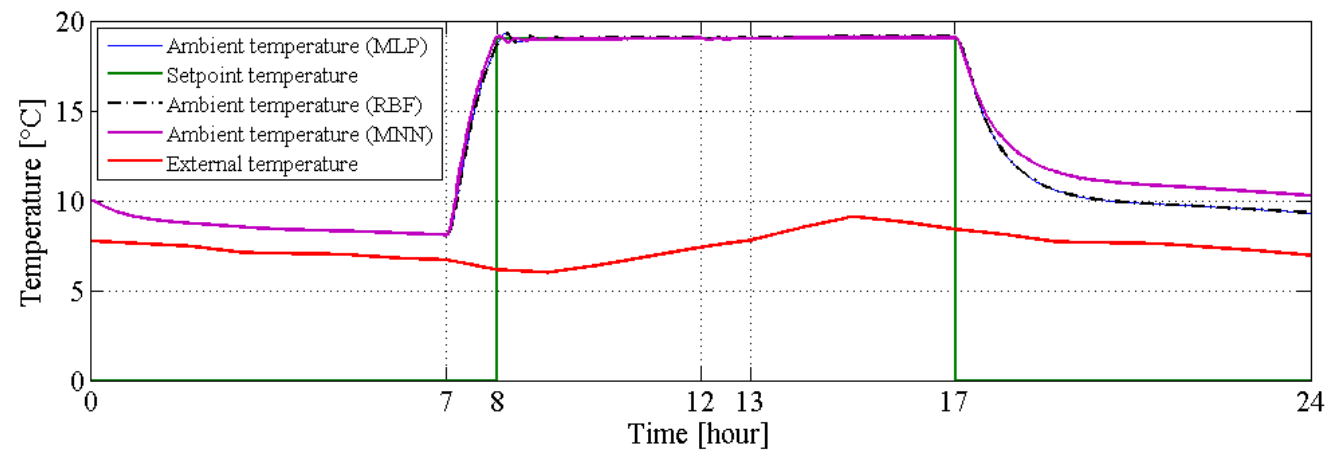

Fig. 11. The output of the process and the reference model

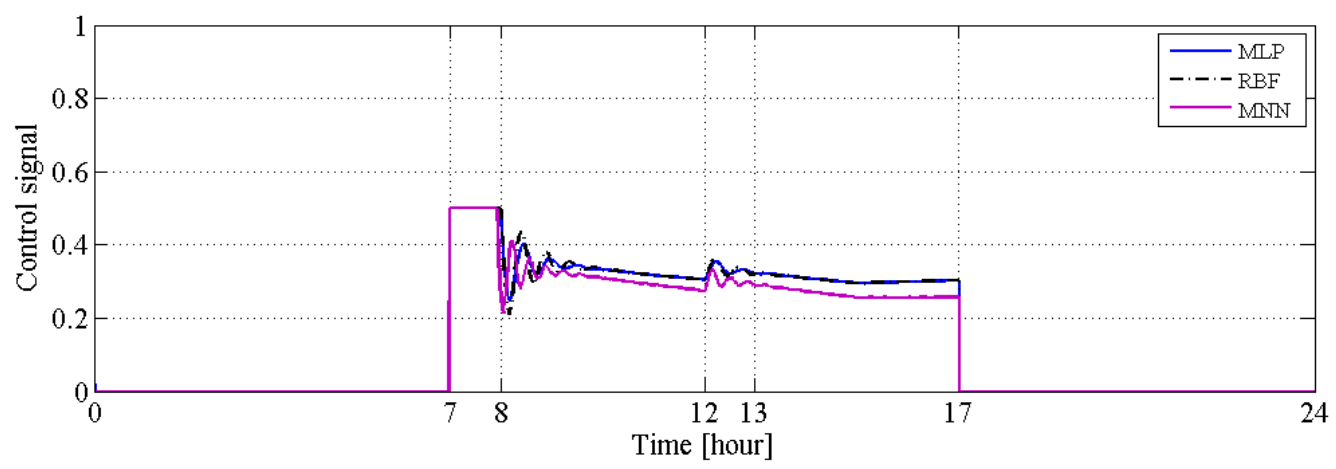

Fig. 12. Control signal 


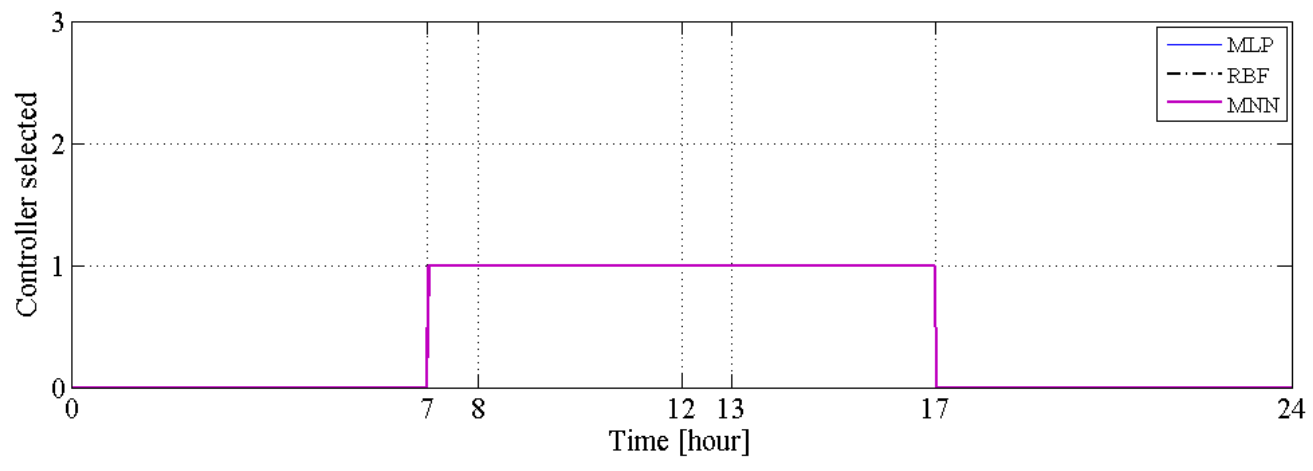

Fig. 13. The controller selected by the supervisor

\section{b.Second case}

The simulation results in the case of medium insulated zone are given in Figs. 14, 15 and 16.

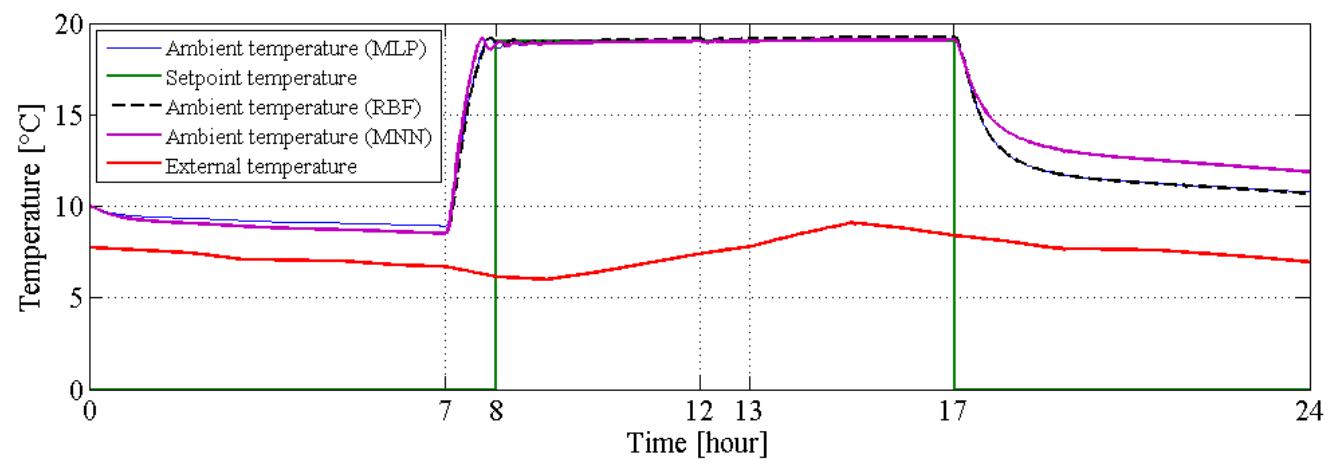

Fig. 14. The output of the process and the reference model

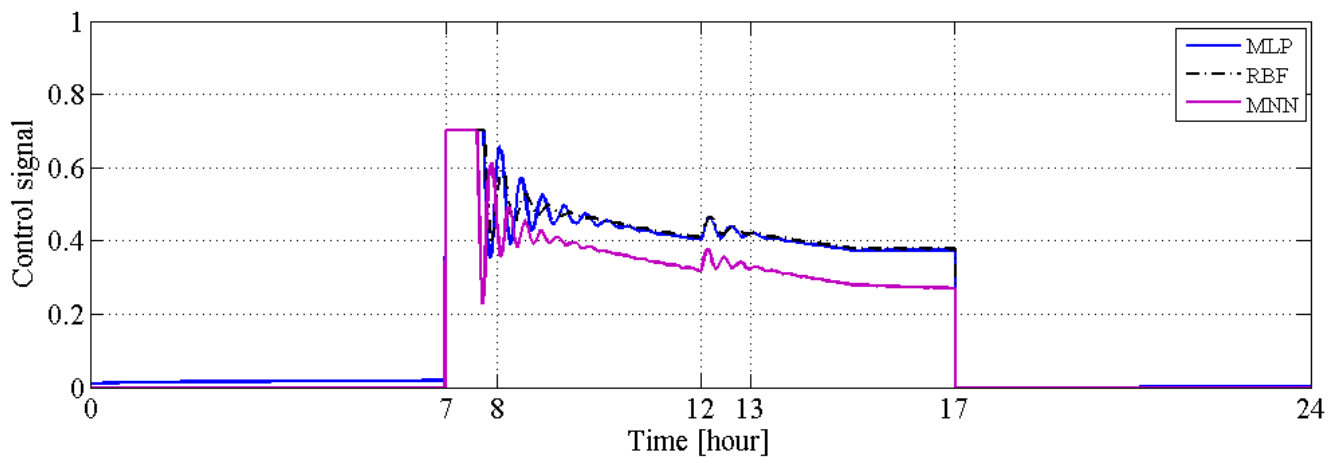

Fig. 15. Control signal

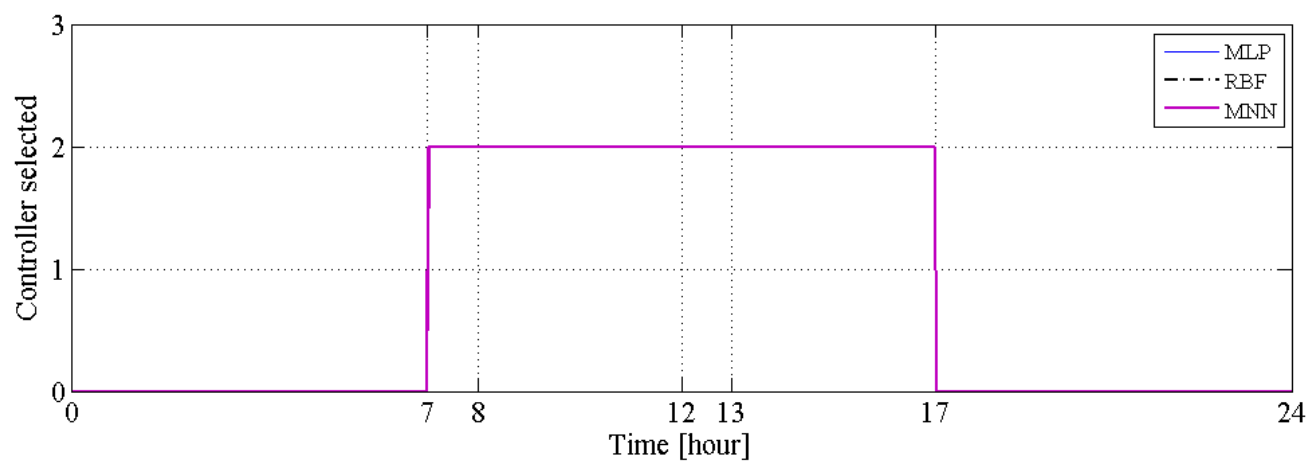

Fig. 16. The controller selected by the supervisor 


\section{c. Third case}

The simulation results in the case of the poorly insulated zone are given in Figs. 17, 18 and 19.

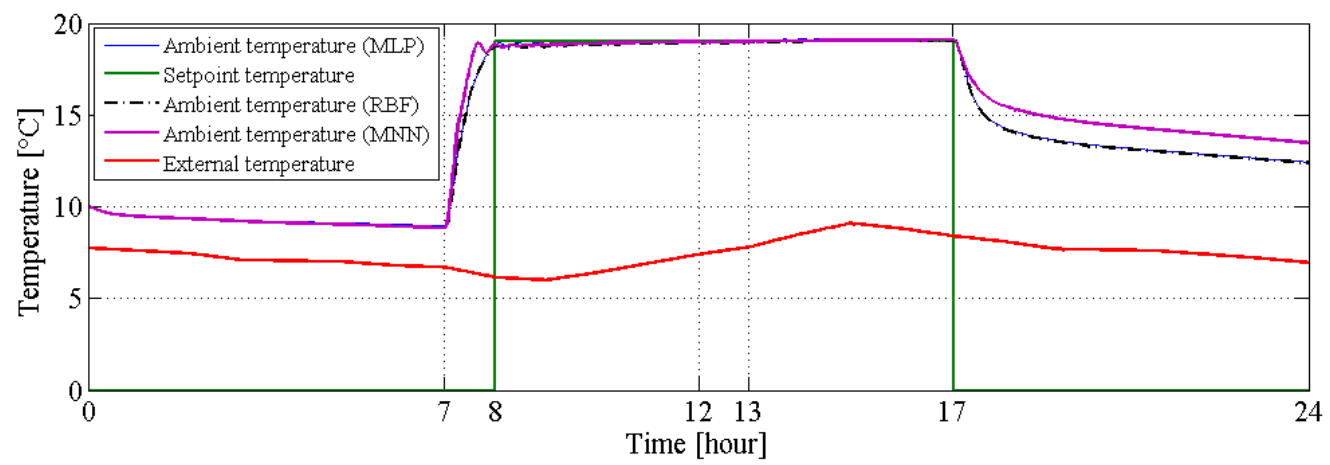

Fig. 17. The output of the process and the reference model

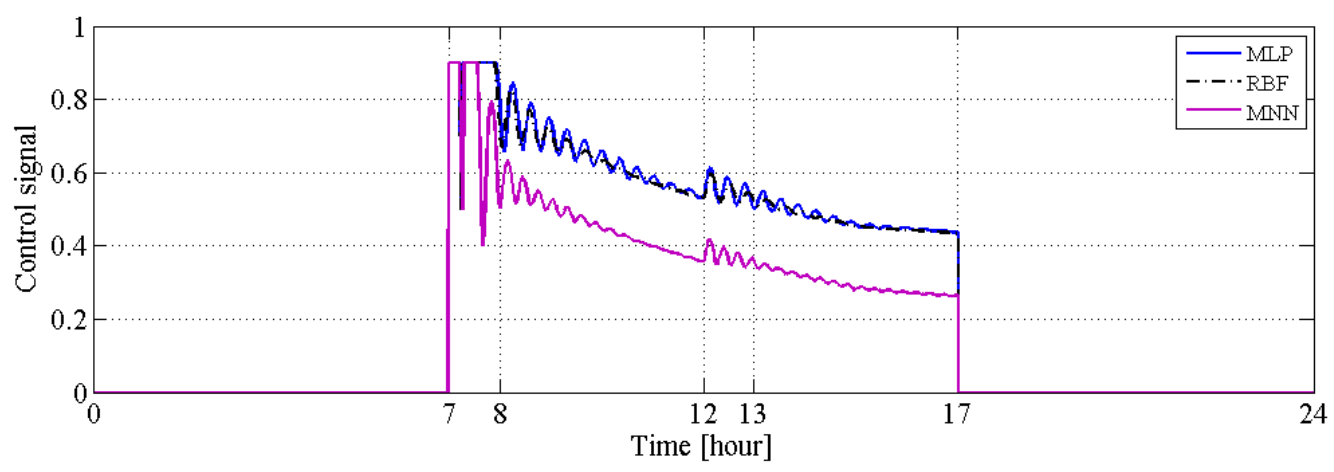

Fig. 18. Control signal

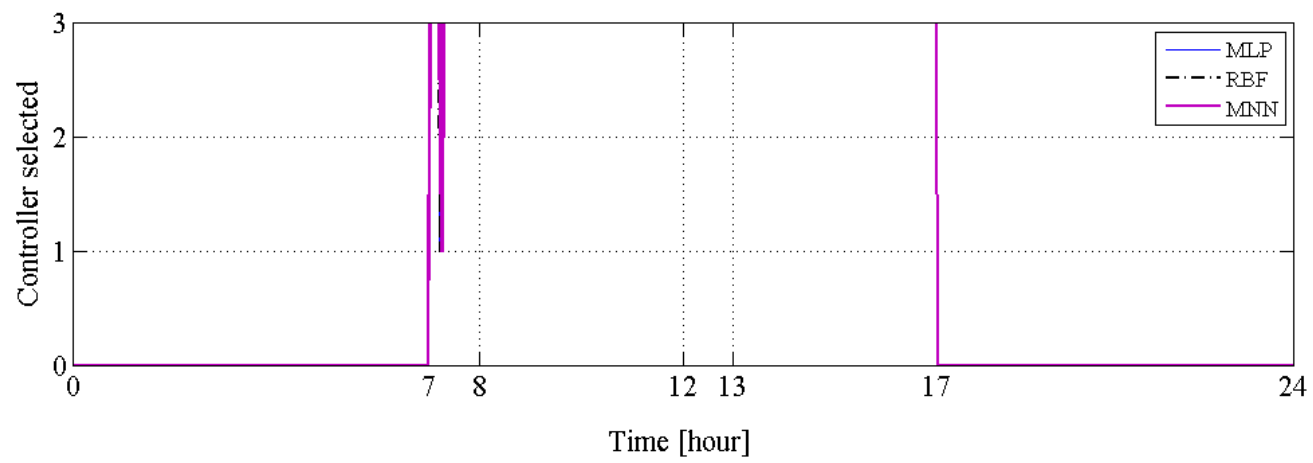

Fig. 19. The controller selected by the supervisor

The mean square errors of the three case with different networks as given in the table below

Table 6

Mean Square Error (MSE) during the occupation period

\begin{tabular}{|c|c|c|c|}
\hline Convective heat transfer coefficients & MLP & $\mathrm{RBF}$ & MNN \\
\hline Well insulation $\left[\begin{array}{lll}0 & 0 & 0\end{array}\right]$ & 0.0087 & 0.0085 & 0.0021 \\
\hline Medium insulation [0.25 0.00010 .25 ] & 0.0089 & 0.0199 & 0.0046 \\
\hline Poor insulation $\left[\begin{array}{lll}0.6 & 0.6 & 0.6\end{array}\right]$ & 0.0119 & 0.0208 & 0.0097 \\
\hline
\end{tabular}

We notice from the Figs. 11, 14 and 17 that the ambient temperature of the process in each case tracks the desired setpoint with a very small mean square errors for three neural networks structures as mentioned in Table 6, despite the large variations in the external temperature presented in the same figures in the red lines. The control signals presented in Figs. 12, 15 and 18 remain in suitable regions which are always less than one (the power is less than $1500 \mathrm{~W}$ ), some oscillations appeared due to the different disturbances. The supervisor in three case select between the three controllers as shown in the 
Figs. 13, 16 and 19 respectively. Generally, we can say that in the first scenario we recognize the building and ensure a good control.

\subsubsection{The second scenario (three days)}

In this scenario, we have simulated the process during the period of three days, for the two first days we consider the zone is well insulated, but for the third day the insulation is decreased to the state of medium insulation. The simulation results are shown in Figs. 20 and 21.

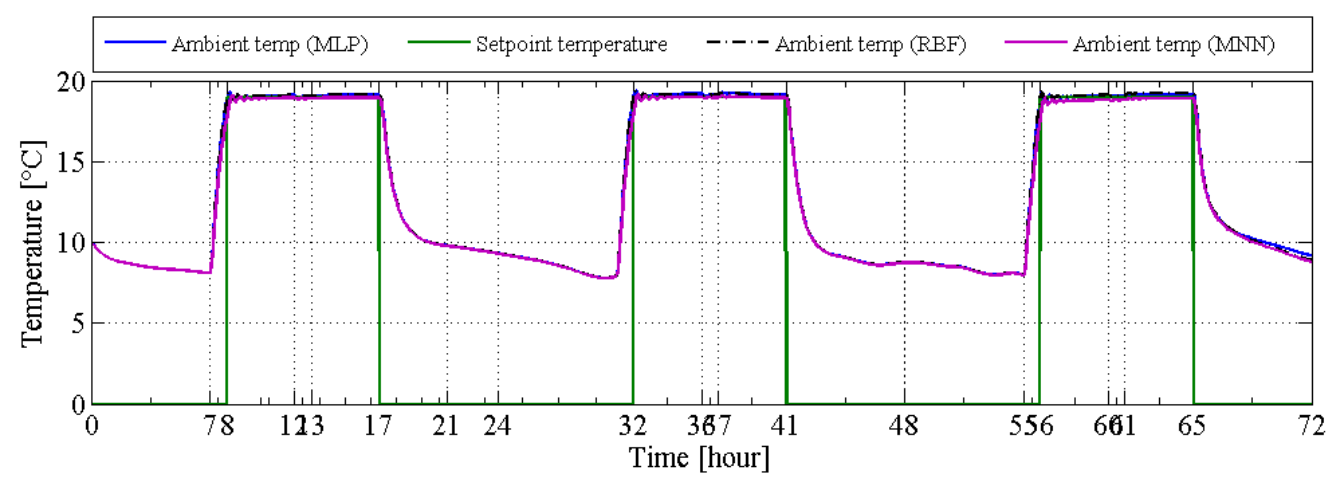

Fig. 20. The output of the process and the reference model

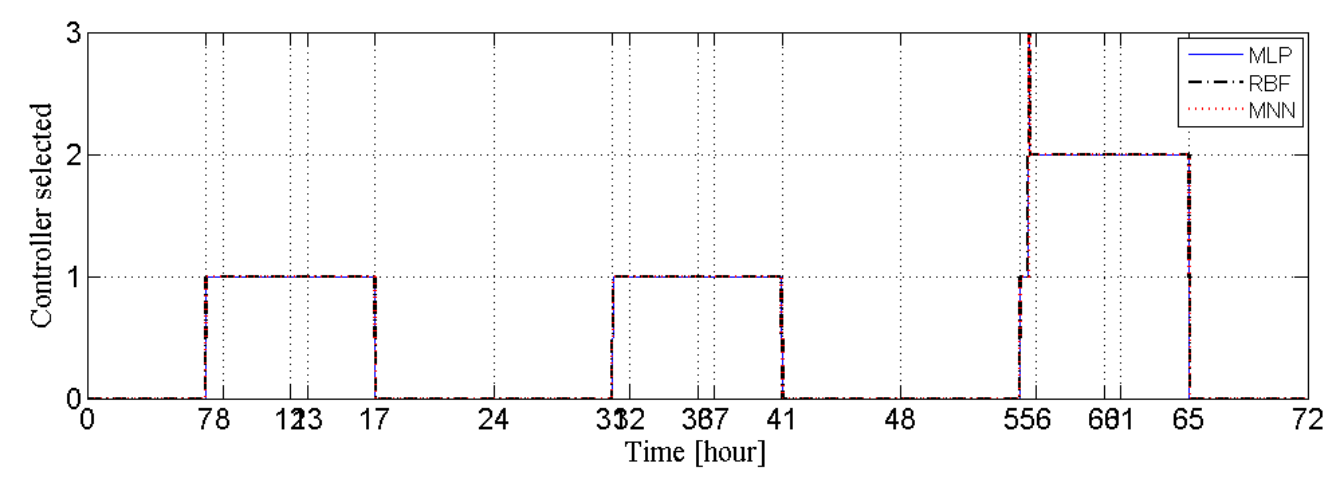

Fig. 21. The controller selected by the supervisor

From Fig. 20, we observe that for three days the output temperature inside the room follows perfectly the desired temperature, in spite of the insulation decline. Fig. 21 shows that the controller selected by the supervisor at each instant, is the appropriate one.

\subsubsection{The third scenario (Performance of supervisory control)}

To validate the performance of supervisory control, we use this method to control another building with other coefficients between the second and the third case. Figures 22, 23 and 24 show the results of simulation.

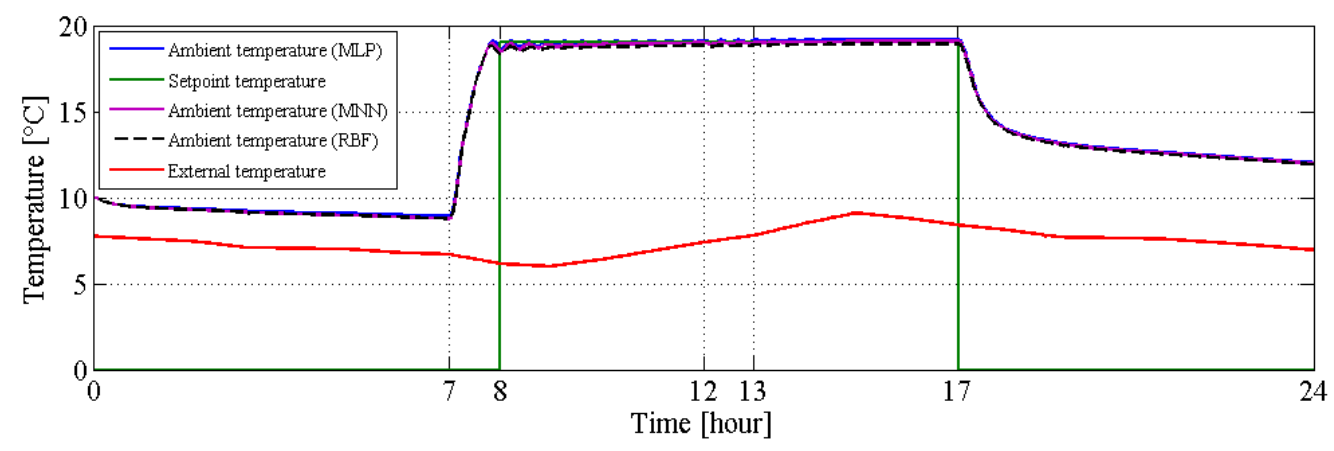


Fig. 22. The output of the process and the reference model

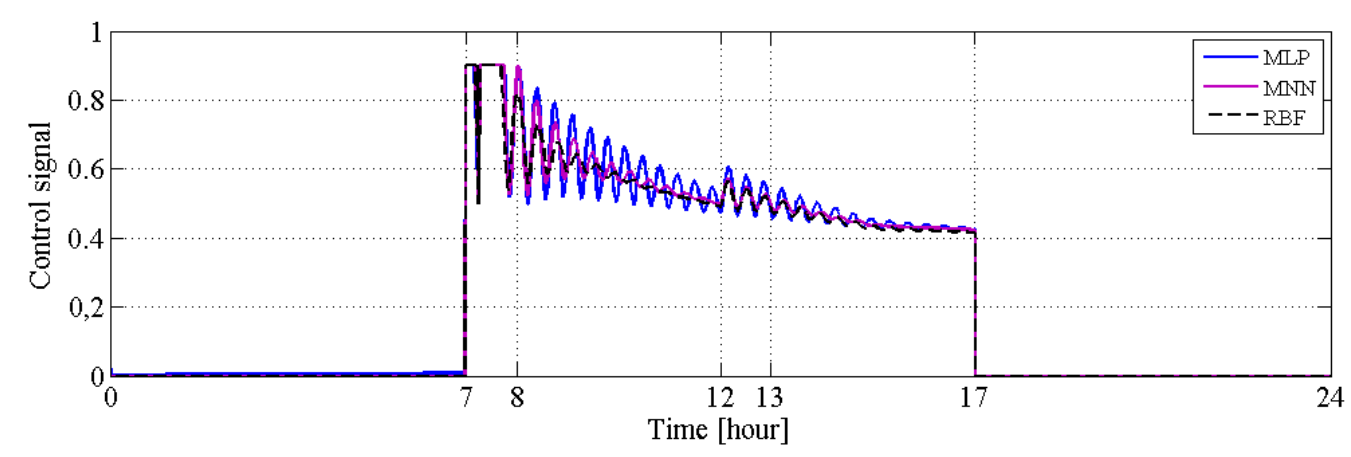

Fig. 23. Control signal

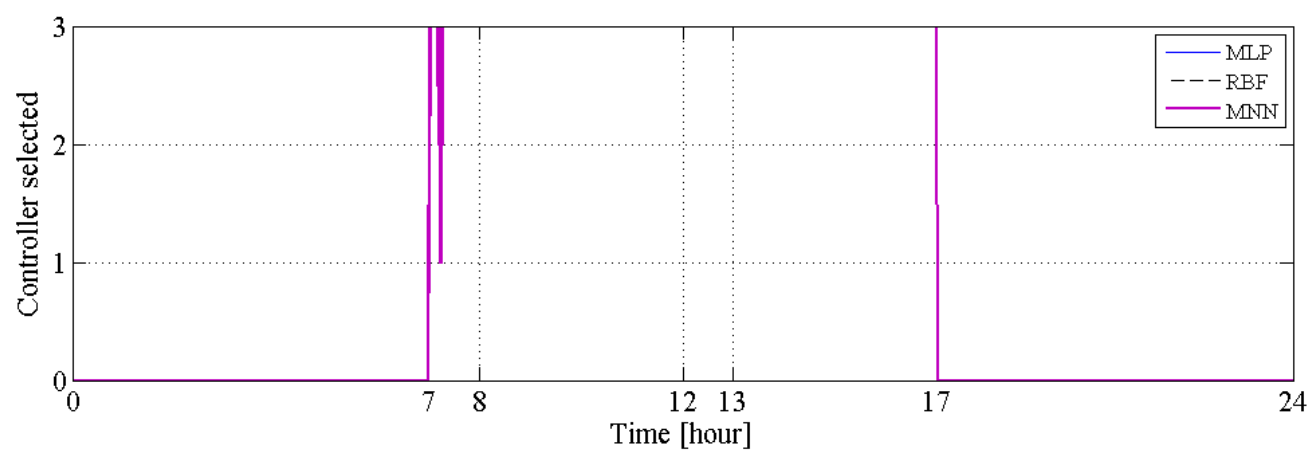

Fig. 24. The controller selected by the supervisor

Table 7

Mean Square Error (MSE) during the occupation period

\begin{tabular}{llll}
\hline Convective heat transfer coefficients & MLP & RBF & MNN \\
\hline$\left[\begin{array}{lll}0.5 & 0.4 & 0.5\end{array}\right]$ & 0.0462 & 0.0173 & 0.0994 \\
\hline
\end{tabular}

Fig. 22 shows that the output of the three neural networks followed the setpoint with very small errors as shown in Table 7. Fig. 23 shows the control signal and Fig. 21 presents the appropriate controller selected by the supervisor.

The results of this scenario reveal that when applied to an unknown configuration of the building, the supervisor selects the appropriate controller to ensure good comfort.

\subsubsection{Numerical evaluation}

To verify the effectiveness and demonstrate the stability of the proposed method and to show the capacity and the efficacy of these neural networks architectures in control and supervision, we define four indices. The first two translate the energy consumed and the comfort of the occupants during the occupation period $\left(8 \mathrm{~h} 00\left(t_{0}\right)\right.$ and $\left.17 \mathrm{~h} 00\left(t_{f}\right)\right)$ [13]. The last two do not have a direct impact on consumption or comfort but are also important in automatic control engineering. They measure the oscillations in the temperature difference and the control signal to get the stability assessment. The objective is to have the best possible indices.

The four indices are given below.

1. The comfort index $\left(I_{\text {comf }}\right)$ corresponds to a difference between the temperature of the room $\left(T_{\text {amb }}\right)$ and the reference temperature $\left(T_{r e f}\right)$, but only during the periods of occupation of the room. 


$$
I_{\text {comf }}=\int_{t_{0}}^{t_{f}}\left|T_{r e f}(t)-T_{\text {amb }}(t)\right| d t
$$

(16)

2. The consumption index ( $\left.I_{\text {cons }}\right)$, used to measure the energy consumption between $t_{0}$ and $t_{f}$.

$$
I_{\text {cons }}=\int_{t_{0}}^{t_{f}} P(t) d t \quad[k W h]
$$

3. The temperature stability index (TSI) corresponds to the temperature oscillations and is given by this equation:

$$
\text { TSI }=\underbrace{\sum\left(\text { localmax }\left(\left|T_{\text {amb }}(t)-T_{\text {ref }}(t)\right|\right)\right)}_{\text {while occupancy }} \quad\left[{ }^{\circ} \mathrm{C}\right]
$$

4. The control stability index (CSI) corresponds to a weighted average of the control variation, and it depend on the time between two successive control values $u(t)$ and $u(t+1)$ which can be considered as a sampling time $T_{s}$.

$$
C S I=\frac{\operatorname{mean}(|u(t+1)-u(t)|)}{T_{s}}
$$

Table 8 shows the performance indices for supervisory control approach using three neural network

\begin{tabular}{|c|c|c|c|c|c|}
\hline $\begin{array}{l}\text { Control } \\
\text { law }\end{array}$ & $\begin{array}{l}\text { Convective heat } \\
\text { transfer coefficients }\end{array}$ & $\begin{array}{l}\text { Comfort } \\
\text { index }\left[{ }^{\circ} \mathrm{Ch}\right]\end{array}$ & $\begin{array}{l}\text { Consumption } \\
\text { index }[\mathrm{kWh}]\end{array}$ & $\begin{array}{l}\text { Temperature } \\
\text { stability index }\left[{ }^{\circ} \mathrm{C}\right]\end{array}$ & $\begin{array}{l}\text { Command } \\
\text { stability index }\end{array}$ \\
\hline \multirow[t]{4}{*}{ MLP } & {$\left[\begin{array}{lll}0 & 0 & 0\end{array}\right]$} & 0.6977 & 5.0429 & 1.4144 & $2.7743 \times 10^{-5}$ \\
\hline & {$\left[\begin{array}{lll}0.25 & 0.0001 & 0.25\end{array}\right]$} & 0.7492 & 6.8030 & 3.7818 & $5.0291 \times 10^{-5}$ \\
\hline & {$\left[\begin{array}{lll}0.6 & 0.6 & 0.6\end{array}\right]$} & 0.8941 & 8.8471 & 3.2205 & $9.4755 \times 10^{-5}$ \\
\hline & {$\left[\begin{array}{lll}0.5 & 0.4 & 0.5\end{array}\right]$} & 1.0708 & 8.3601 & 4.7750 & $8.1774 \times 10^{-5}$ \\
\hline \multirow[t]{4}{*}{$\mathrm{RBF}$} & {$\left[\begin{array}{lll}0 & 0 & 0\end{array}\right]$} & 0.7364 & 5.0455 & 2.7176 & $4.2183 \times 10^{-5}$ \\
\hline & {$\left[\begin{array}{lll}0.25 & 0.0001 & 0.25\end{array}\right]$} & 1.1449 & 6.7092 & 4.7764 & $2.6900 \times 10^{-5}$ \\
\hline & {$\left[\begin{array}{lll}0.6 & 0.6 & 0.6\end{array}\right]$} & 0.9379 & 8.7148 & 3.4005 & $5.2405 \times 10^{-5}$ \\
\hline & {$\left[\begin{array}{lll}0.5 & 0.4 & 0.5\end{array}\right]$} & 1.6428 & 8.1061 & 6.0983 & $2.5174 \times 10^{-5}$ \\
\hline \multirow[t]{4}{*}{$\mathrm{MNN}$} & {$\left[\begin{array}{lll}0 & 0 & 0\end{array}\right]$} & 0.3481 & 4.1462 & 2.4146 & $3.3145 \times 10^{-5}$ \\
\hline & {$\left[\begin{array}{llll}0.25 & 0.0001 & 0.25\end{array}\right]$} & 0.5201 & 4.8656 & 2.4228 & $3.4954 \times 10^{-5}$ \\
\hline & {$\left[\begin{array}{lll}0.6 & 0.6 & 0.6\end{array}\right]$} & 0.7136 & 5.5843 & 2.8914 & $5.2678 \times 10^{-5}$ \\
\hline & {$\left[\begin{array}{lll}0.5 & 0.4 & 0.5\end{array}\right]$} & 0.7502 & 8.2348 & 3.6789 & $3.5558 \times 10^{-5}$ \\
\hline
\end{tabular}
architectures (MLP, RBF and MNN) in the first and third scenarios. For the second scenario, the values are approximately the same with the first scenario, for this reason, they are not considered in this paper.

Table 8

From the results given in Table 8, we note that on the one hand, the values of the comfort index are very low which specify that the error between the setpoint and the ambient output temperature converges to zero during the occupation time and that means comfort is maintained. In the other hand, the small values of the consumption index reflect the low energy consumption. On the basis of the two last columns of this table, we remark that the maximum local points are not far from the setpoint and the command signal is stable. When we compare between the three architectures of neural networks using different columns, we record that those of MNN are better than those of MLP and RBF. From Table 8, we notice that the MNN gives the best results in terms of tracking, this due to the memory elements that gives the network a great ability to converge. 


\section{Conclusions and perspectives}

This paper presents a new strategy of supervisory control based on three model/controller pairs to regulate the ambient temperature around the desired setpoint in a building zone. The control scheme is based on switching and tuning between three predesigned pairs of model/controller, we have achieved the goal of reducing the energy consumed and maintaining a certain level of thermal comfort for the occupants. This approach takes in consideration the different disturbances and constraints. In this work, we have simulated and illustrated three types of neural networks (MLP, RBF and MNN) used to define the different identifiers and controllers of highly complex nonlinear thermal system.

The simulation results have shown the validity and efficacy of these architectures. After the comparative study based on their performance indices, we have concluded despite the complexity and the long simulation time of MNN neural networks it gives better results compared to the other two networks (MLP and RBF) that is why it is interesting to choose this type of networks to control this kind of system.

The future work will focus on the use of building management data base to tune this controller, integration of different criteria, theoretical study of stability and robustness of this approach and other methods based on adaptive synchronization of multi-agent systems with resilience to communication link faults.

\section{Acknowledgements}

This work was partially supported by the ministry of higher education and scientific research of Algeria.

\section{References}

[1] T. B. Johansson, A. Patwardhan, N. Nakicenovic and L.G. Echeverri. (2012). "Glabal Energy Assessment (GEA)". Cambridge university press. https://doi.org/10.1017/CBO9780511793677

[2] P. Kyle, L. Clarke, F. Rong and S. Smith (2010) "Climate policy and the long-term evolution of the US buildings sector", The Energy Journal, p. 145-172. https://doi.org/10.5547/ISSN0195-6574-EJ-Vol31-No2-6

[3] J. Eom, L. Clarke, S. Kim, P. Kyle and P. Patel. (2012) "China's building energy demand: Long-term implications from a detailed assessment", Energy, vol. 46, no 1, p. 405-419. https://doi.org/10.1016/j.energy.2012.08.009

[4] D. Ürge-Vorsatz, L. Cabeza, S. Serrano, C. Barreneche and K. Petrichenko. (2015) "Heating and cooling energy trends and drivers in buildings", Renewable and Sustainable Energy Reviews, vol. 41, p. 85-98. https://doi.org/10.1016/j.rser.2014.08.039

[5] L. Pérez-Lombard, J. Ortiz and C. Pout. (2008) "A review on buildings energy consumption information", Energy and Buildings, vol. 40, no. 3, pp. 394-398. https://doi.org/10.1016/j.enbuild.2007.03.007

[6] R. Yusof, H. Selamat and S. Attaran. (2014) "Short review on HVAC components, mathematical model of HVAC system and different PID controllers", International Review of Automatic Control, vol. 7, no. 3, pp. 263-270.

[7] S. Soyguder, M. Karakose and H. Alli. (2009) "Design and simulation of self-tuning PID-type fuzzy adaptive control for an expert HVAC system", Expert Systems with Applications, vol. 36, no. 3, pp. 4566-4573. https://doi.org/10.1016/j.eswa.2008.05.031

[8] A. Keshtkar and S. Arzanpour. (2017) "An adaptive fuzzy logic system for residential energy management in smart grid environments". Applied Energy, vol. 186, pp. 68-81. https://doi.org/10.1016/j.apenergy.2016.11.028

[9] M.W. Ahmad, M. Mourshed, B. Yuce, Y. Rezgui. (2016) "Computational intelligence techniques for HVAC systems: A review", Building Simulation, vol. 9, no. 4, pp. 359-398. https://doi.org/10.1007/s12273-016-0285-4

[10] Chi, R., Lv, Y., \& Huang, B. (2019). Distributed iterative learning temperature control for multi-zone HVAC system. Journal of the Franklin Institute. https://doi.org/10.1016/j.jfranklin.2019.10.007

[11] T. Darure, V. Puig, J. Yamé, F. Hamelin and Y. Wang. (2018) "Distributed Model Predictive Control applied to a VAV based HVAC system based on Sensitivity Analysis". IFAC-PapersOnLine, vol. 51, no. 20, pp. 259-264. https://doi.org/10.1016/j.ifacol.2018.11.023

[12] H. Huang, L. Chen and E. Hu. (2015) "A neural network-based multi-zone modelling approach for predictive control system design in commercial buildings", Energy and Buildings, vol. 97, pp. 86-97. https://doi.org/10.1016/j.enbuild.2015.03.045

[13] P. D. Moroşan, R. Bourdais, D. Dumur and J. Buisson. (2010) "Building temperature regulation using a distributed model predictive control", Energy and Buildings, vol. 42, no. 9, pp. 1445-1452. https://doi.org/10.1016/j.enbuild.2010.03.014 
[14] P. Satrio, T. M. I. Mahlia, N. Giannetti, and K. Saito. (2019) "Optimization of HVAC system energy consumption in a building using artificial neural network and multi-objective genetic algorithm". Sustainable Energy Technologies and Assessments, vol. 35, pp. 48-57. https://doi.org/10.1016/j.seta.2019.06.002

[15] N. Kampelis, A. Ferrante, D. Kolokotsa, K. Gobakis, L. Standardi and C. Cristalli. (2017) "Thermal comfort evaluation in HVAC Demand Response control". Energy Procedia, vol. 134, pp. 675-682. https://doi.org/10.1016/j.egypro.2017.09.587

[16] Z. Deng and Q. Chen. (2019) "Simulating the impact of occupant behavior on energy use of HVAC systems by implementing a behavioral artificial neural network model". Energy and Buildings, vol. 198, pp. 216-227. https://doi.org/10.1016/j.enbuild.2019.06.015

[17] A. Aryal and B. Becerik-Gerber. (2018) "Energy consequences of Comfort-driven temperature setpoints in office buildings". Energy and Buildings, vol. 177, pp. 33-46. https://doi.org/10.1016/j.enbuild.2018.08.013

[18] P. Aparicio-Ruiz, E. Barbadilla-Martín, J. M. Salmerón-Lissén and J. Guadix-Martín. (2018). "Building automation system with adaptive comfort in mixed mode buildings". Sustainable cities and society, vol. 43, pp. 77-85. https://doi.org/10.1016/j.scs.2018.07.028

[19] A. Afram and F. Janabi-Sharifi. (2017). "Supervisory model predictive controller (MPC) for residential HVAC systems: Implementation and experimentation on archetype sustainable house in Toronto". Energy and Buildings, vol. 154, pp. $268-282$. https://doi.org/10.1016/j.enbuild.2017.08.060

[20] W. Li, J. Zhang and T. Zhao. (2019) "Indoor thermal environment optimal control for thermal comfort and energy saving based on online monitoring of thermal sensation". Energy and Buildings, vol. 197, pp. 57-67. https://doi.org/10.1016/j.enbuild.2019.05.050

[21] S. Kersting and M. Buss. (2018) "How to Systematically Distribute Candidate Models and Robust Controllers in Multiple-Model Adaptive Control: A Coverage Control Approach", IEEE Transactions on Automatic Control, vol. 63, no. 4, pp. 1075-1089. https://doi.org/10.1109/TAC.2017.2731946

[22] Z. Han and K. Narendra. (2012) "New Concepts in Adaptive Control Using Multiple Models", IEEE Transactions on Automatic Control, vol. 57, no. 1, pp. 78-89. https://doi.org/10.1109/TAC.2011.2152470

[23] X. Li, C. Jia, D. Liu and D. Ding. (2014) "Nonlinear adaptive control using multiple models and dynamic neural networks", Neurocomputing, vol. 136, pp. 190-200. https://doi.org/10.1016/j.neucom.2014.01.013

[24] S. Wang and Z. Ma. (2008) "Supervisory and Optimal Control of Building HVAC Systems: A Review", HVAC\&R Research, vol. 14, no. 1, pp. 3-32. http://doi.org/10.1080/10789669.2008.10390991

[25] K. S. Narendra and K. Parthasarathy, "Identification and control of dynamical systems using neural networks", IEEE Transactions on Neural Networks, vol. 1, no. 1, pp. 4-27, March 1990. https://doi.org/10.1109/72.80202

[26] G. Cybenko. (1989) "Approximation by superposition of a sigmoidal function". Mathematics of control, signals and systems, vol. 2, no. 4 , pp. 303-314.

[27] I. Rivals, L. Personnaz, G. Dreyfus and J. L. Ploix. (1995) "Modélisation, classification et commande, Par réseaux de neurones : principes fondamentaux, Méthodologie de conception et illustrations industrielles". Les réseaux de neurones pour la modélisation et la commande de procédés, JP Corriou, ed.(Lavoisier Tec \& Doc).

[28] J. Moon, J. Lee and S. Kim. (2014) "Evaluation of Artificial Neural Network-Based Temperature Control for Optimum Operation of Building Envelopes", Energies, vol. 7, no. 11, pp. 7245-7265. https://doi.org/10.3390/en7117245

[29] A. Berry and H. Alaskr. (2018) "Using Artificial Neural Network Technique to Save Energy Consumption in HVAC Systems", International Journal of Applied Engineering Research, vol. 13, no. 12, pp. 10517-10524.

[30] H Hagras. (2008) "Employing computational intelligence to generate more intelligent and energy efficient living spaces", International Journal of Automation and Computing, vol. 5, no. 1, pp. 1-9. https://doi.org/10.1007/s11633-008-0001-7

[31] M.A.R. Biswas, M.D. Robinson and N. Fumo. (2016) "Prediction of residential building energy consumption: A neural network approach", Energy, vol. 117, pp. 84-92. https://doi.org/10.1016/j.energy.2016.10.066

[32] S. Prakash, N.P. Gopinath and J. Suganthi. (2018) "Wind and solar energy forecasting system using artificial neural networks", International Journal of Pure and Applied Mathematics Energy, vol. 118, no. 5, pp. 845-854.

[33] R. Ata. (2015) "RETRACTED: Artificial neural networks applications in wind energy systems: a review", Renewable and Sustainable Energy Reviews, vol. 49, pp. 534-562. https://doi.org/10.1016/j.rser.2015.04.166

[34] S Mishra, P Dash. (2018) "Short term wind speed prediction using multiple kernel pseudo inverse neural network", International Journal of Automation and Computing, vol. 15, no. 1, pp. 66-83. https://doi.org/10.1007/s11633-017-1086-7

[35] A.H. Elsheikh, S.W. Sharchir and all. (2019) "Modeling of solar energy systems using artificial neural network: A comprehensive review", Solar Energy, vol. 180, pp. 622-639. https://doi.org/10.1016/j.solener.2019.01.037

[36] CO. SikiruSurajudeen, A. Muhammad Irsyad and all. (2018) "Modeling of Solar Radiation Using Artificial Neural Network for Renewable Energy Application", IOSR Journal of Applied Physics, vol. 10, no. 2, pp. 06-12. https://doi.org/10.9790/4861 -1002030612

[37] R Tan, Y Cao. (2019) "Multi-layer Contribution Propagation Analysis for Fault Diagnosis", International Journal of Automation and Computing, vol. 16, no. 1, pp. 40-51. https://doi.org/10.1007/s11633-018-1142-y 
[38] A. Ouaret, H. Lehouche, B. Mendil, S. Fredj and H. Guéguen. (2017) "Supervisory control of a building heating system based on radial basis function neural networks". In 5th International Conference on Electrical Engineering-Boumerdes (ICEE-B), pp. 1-6. https://doi.org/10.1109/ICEE-B.2017.8192182

[39] SIMBAD Building and HVAC Toolbox, Version 4.0 ed, CSTB, 84, avenue Jean Jaurés- Champs-sur-Marne-B-P 2- F-77421 MarnelaValléeCedex 2, March 2005.

[40] J. Liu, Radial Basis Function (RBF) Neural Network Control for Mechanical Systems. Springer, 2013. https://doi.org/10.1007/978-3-64234816-7

[41] I. Zaidi, M. Chtourou and M. Djemel. (2019) "Robust Neural Control of Discrete Time Uncertain Nonlinear Systems Using Sliding Mode Backpropagation Training Algorithm", International Journal of Automation \& Computing, vol. 16, no. 2, pp. 213-225. https://doi.org/10.1007/s11633-017-1062-2

[42] P. Sastry, G. Santharam and K. Unnikrishnan. (1994) "Memory neuron networks for identification and control of dynamical systems", IEEE Transactions on Neural Networks, vol. 5, no. 2, pp. 306-319. https://doi.org/10.1109/72.279193

[43] K. Singh, A. Basant, A. Malik and G. Jain. (2009) "Artificial neural network modeling of the river water quality—A case study", Ecological Modelling, vol. 220, no. 6, pp. 888-895. https://doi.org/10.1016/j.ecolmodel.2009.01.004

[44] O. Isaac Oludare, A. Jantan and all. (2018) "State-of-the-art in artificial neural network applications: A survey", Heliyon, vol. 4, no. 11. https://doi.org/10.1016/j.heliyon.2018.e00938

[45] C. Dash, A. Behera, S. Dehuri and S. Cho. (2016) "Radial basis function neural networks: a topical state-of-the-art survey", Open Computer Science, vol. 6, no. 1, pp. 33-63. https://doi.org/10.1515/comp-2016-0005

[46] C. Arteaga and I. Marrero. (2013) "Universal approximation by radial basis function networks of Delsarte translates", Neural Networks, vol. 46, pp. 299-305. https://doi.org/10.1016/j.neunet.2013.06.011

[47] Y. Wu, H. wang, B. Zhang and k. Du. (2012) "Using Radial Basis Function Networks for Function Approximation and Classification", ISRN Applied Mathematics, vol. 2012, pp. 1-34. http://dx.doi.org/10.5402/2012/324194

[48] J. Yang, J. Na, G. Gao and C. Zhang. (2018) "Adaptive Neural Tracking Control of Robotic Manipulators with Guaranteed NN Weight Convergence", Complexity, vol. 2018, pp. 1-11. https://doi.org/10.1155/2018/7131562

[49] A.S. Yilmaz and Z. Ozer. (2009) "Pitch angle control in wind turbines above the rated wind speed by multi-layer perceptron and radial basis function neural networks", Expert Systems with Applications, vol. 36, no. 6, pp. 9767-9775. https://doi.org/10.1016/j.eswa.2009.02.014

[50] R. Kumar, S. Srivastava and J.R.P. Gupta. (2016) "Modeling and adaptive control of nonlinear dynamical systems using radial basis function network", Soft Computing, vol. 21, no. 15, pp. 4447-4463. https://doi.org/10.1007/s00500-016-2447-9

[51] F. L. Luo and R. Unbehauen (1998). Applied neural networks for signal processing. Cambridge university press.

[52] N. K. Kasabov (1998). Foundations of neural networks, fuzzy systems, and knowledge engineering. ( $2^{\text {nd }}$ ed.). A Bradford Book/The MIT Press.

[53] P. Poddar and K. P. Unnikrishnan (1991). Memory neuron networks: A prolegomenon. General Motors Corporation. Research Laboratories. Computer Science Department.

[54] R. J. Williams and D. Zipser. (1989) "A learning algorithm for continually running recurrent neural networks", Neural Computation, vol. 1, no. 2, pp. 270-280. https://doi.org/10.1162/neco.1989.1.2.270

[55] K. P. Unnikrishnan and K. P. Venugopal. (1994) "Alopex: A correlation-based learning algorithm for feedforward and recurrent neural networks", Neural Computation, vol. 6, pp. 467488. https://doi.org/10.1162/neco.1994.6.3.469

[56] S. Haykin, B. Widrow. (2003) Least-Mean-Square Adaptive Filters. Wiley, New York.

[57] F.A. Guerra, L.S. Coelho. (2008) "Multi-step ahead nonlinear identification of Lorenz's chaotic system using radial basis neural network with learning by clustering and particle swarm optimization", Chaos, Solitons Fractals, vol. 35, no. 5, pp. 967-979. https://doi.org/10.1016/j.chaos.2006.05.077

[58] D.F. Cook, C.T. Ragsdale, R.L. Major. (2000) "Combining a neural network with a genetic algorithm for process parameter optimization", Engineering Applications of Artificial Intelligence, vol. 13, no. 4, pp. 391-396. https://doi.org/10.1016/s0952-1976(00)00021-x

[59] E. Chacón, F. Szigeti and O. Camacho. (1996) "Integral automation of industrial complexes based on hybrid systems", ISA Transactions, vol. 35, no. 4, pp. 305-319. https://doi.org/10.1016/S0019-0578(96)00032-8

[60] J. Hespanha, D. Liberzon, A. Stephen Morse, B. Anderson, T. Brinsmead and F. De Bruyne. (2001) "Multiple model adaptive control. Part 2: switching", International Journal of Robust and Nonlinear Control, vol. 11, no. 5, pp. 479-496. https://doi.org/10.1002/rnc.594

[61] H. Lehouche, H. Guéguen and B. Mendil. (2012) "Set-Point Supervisory Control Methodology for a Nonlinear Continuous Stirred Tank Reactor Process", Arabian Journal for Science and Engineering, vol. 37, no. 3, pp. 831-849. https://doi.org/10.1007/s13369-012-0188-3

[62] H. Lehouche, B. Mendil and H. Guéguen. (2012) "Supervisory control based on closed-loop adaptive control approach of nonlinear systems: application to CSTR process", Asian Journal of Control, vol. 14, no. 1, pp. 258-270. https://doi.org/10.1002/asjc.317 